\title{
69. DETAILED CRUSTAL STRUCTURE OF NORTHERN YAMATO BASIN ${ }^{1}$
}

\author{
M. Shinohara, ${ }^{2,3}$ N. Hirata, ${ }^{2}$ H. Nambu, ${ }^{2}$ K. Suyehiro, ${ }^{4}$ T. Kanazawa,${ }^{5}$ and H. Kinoshita ${ }^{6}$
}

\begin{abstract}
In September 1989, an ocean broadband digital downhole seismometer (OBDS) was installed at Hole 794D in the northern Yamato Basin by the Ocean Drilling Program (ODP). We conducted a high-resolution refraction/reflection experiment using the OBDS and nine ocean-bottom seismometers (OBS's), which were deployed by the Tansei-maru. We continuously recorded signals from the OBDS in digital form on the JOIDES Resolution for about 2 days.

The OBDS had a three-component feed-back-type accelerometer. The signals were sampled at $80 \mathrm{~Hz}$ with 16-bit resolution. The OBS's recorded signals for about 2 weeks by the direct analog recording method. The five OBS's, which were closely spaced every $2800 \mathrm{~m}$ near Hole 794D, and the OBDS formed a three-dimensional sub-array. The air-gun profiles consisted of two circles and two linear lines. Air guns were shot every $60 \mathrm{~s}$ at $10 \mathrm{MPa}$ with two 9-L or a single 17-L, chamber. Signals from a single channel hydrophone streamer were also recorded with a personal computer system in digital form.

We determined the velocity structure near the profiles using the OBDS and four OBS's that were deployed every $25 \mathrm{~km}$. A two-dimensional (2-D) velocity model was constructed as follows: first, one-dimensional velocity structures under each OBS were derived by the tau- $p$ inversion method; second, 2-D velocity structures under the linear profiles were derived by the forward 2-D ray tracing method.

A sedimentary layer with a small velocity gradient exists just beneath the seafloor. The layer has a velocity of $1.7 \mathrm{~km} / \mathrm{s}$ and is 200-700 m thick. The layer corresponds to the transparent layer on the reflection profile. An acoustic basement with a $P$-wave velocity of $4.2-4.5 \mathrm{~km} / \mathrm{s}$ underlies the sedimentary layer. The acoustic basement layer has a velocity gradient of $0.25 \mathrm{~s}^{-1}$ and is $2-3 \mathrm{~km}$ thick. A layer with a velocity of $6.2 \mathrm{~km} / \mathrm{s}$ underlies the acoustic basement layer. The velocity gradient in the $6.2 \mathrm{~km} / \mathrm{s}$ layer is less than $0.2 \mathrm{~s}^{-1}$. We could not determine the thickness of the $6.2 \mathrm{~km} / \mathrm{s}$ layer because of the lack of deep penetration of refracted waves down to the Moho. However, the thickness of the $6.2 \mathrm{~km} / \mathrm{s}$ layer is estimated to be more than $6 \mathrm{~km}$ based on the depth of penetration of refracted wave through the $6.2 \mathrm{~km} / \mathrm{s}$ layer.

The upper crustal structure is similar to that found in the southern Yamato Basin, where the entire crust is neither typical oceanic nor continental.
\end{abstract}

\section{INTRODUCTION}

The Japan Sea is one of the backarc basins in the western Pacific. It comprises the Japan Basin in the northwest and the Yamato Basin in the southeast, and is divided by the Yamato Rise (Fig. 1). The seafloor depths of the two basins are nearly constant at about $3500 \mathrm{~m}$ and $2500 \mathrm{~m}$, respectively.

A number of models have been proposed to explain the formation and evolution of the Japan Sea from the seismic structure of the lithosphere (Abe and Kanamori, 1970; Evans et al., 1978), magnetic anomalies (Isezaki et al., 1971; Isezaki and Uyeda, 1973; Isezaki, 1975; Seama and Isezaki, 1990), paleomagnetic evidence on land (Otofuji and Matsuda, 1984; Otofuji et al. 1985; Otofuji and Matsuda, 1987), and heat-flow data (Yasui et al., 1968; Yoshii, 1972; Tamaki, 1986; Yamano et al., 1987). One of the main objectives of Legs $127 / 128$ drilling was to obtain ground-truth evidence to solve this major problem.

Any valid model should be able to explain the seismic structure of the Japan Sea crust, which appears to be highly variable. The seismic structure of the Yamato Rise suggests a continental crustal structure, though its thickness is undetermined (Murauchi, 1972; Ludwig et al., 1975). The Japan Basin has a typical oceanic crustal thickness of $8 \mathrm{~km}$ (Murauchi, 1972; Ludwig et al., 1975). The seismic crustal structure of the Yamato Basin is $14 \mathrm{~km}$ thick, which is twice

\footnotetext{
${ }^{1}$ Tamaki, K., Suyehiro, K., Allan, J., McWilliams, M., et al., 1992. Proc. ODP. Sci. Results, 127/128, Pt. 2: College Station, TX (Ocean Drilling Program).

${ }^{2}$ Department of Earth Sciences, Faculty of Science, Chiba University, Chiba 260,

${ }^{3}$ Present address: Ocean Research Institute, the University of Tokyo, Tokyo 164,

${ }^{4}$ Ocean Research Institute, the University of Tokyo, Tokyo 164. Japan.

${ }^{5}$ Faculty of Science, the University of Tokyo, Tokyo 113 , Japan.

${ }^{6}$ Earthquake Research Institute, the University of Tokyo, Tokyo 113, Japan.
} Japan. Japan. as thick as a typical oceanic basin. However, the velocity in each layer is similar to that of oceanic crust except that the $P$-wave velocity in the uppermost mantle $\left(P_{\mathrm{n}}\right.$ velocity) is lower than a normal oceanic $P_{\mathrm{n}}$ velocity (Murauchi, 1972; Ludwig et al., 1975; Hirata et al., 1987; Katao, 1988; Chung et al., 1990).

An anisotropic velocity model for the uppermost mantle beneath the Japan Sea has been proposed by Okada et al. (1978). The anisotropy in the uppermost mantle is confirmed by an OBS array study in the southern Yamato Basin, where the maximum velocity direction is perpendicular to the strike of the northwest Japan arc (Hirata et al., 1989). The crustal seismic anisotropy in the studied region is reported by Hirata et al. (this volume).

The use of OBS's in refraction experiments has been shown to improve the quality and resolution of the seismic structural model as evidenced in the 1985 OBS and multichannel seismic profiling (MCS) experiment in the southwestern Yamato Basin (Hirata et al., $1987,1989)$. The use of a downhole seismometer in recent refraction experiments has proven to be useful in obtaining higher quality data sets and a high-resolution seismic structure (Stephen et al., 1983; Swift et al, 1988; Little and Stephen, 1985; Stephen and Harding, 1983; Jacobson et al., 1984; Shearer et al., 1986a; Whitmarsh et al., 1986; Duennebier et al., 1987; Byrne et al., 1987; Bee and Bibee, 1989), and in studying of seismic anisotropy and lateral heterogeneity (Stephen, 1985; 1988; Swift and Stephen, 1989; Shearer and Orcutt, 1985; Shearer et al., 1986b). A refraction experiment using both a downhole seismometer and OBS's, which promises greater resolution of seismic structures especially in laterally heterogeneous region, can thus contribute important details relevant to understanding the tectonic evolution of a particular region.

In September 1989, an ocean broadband downhole seismometer (OBDS) was deployed at Hole 794D in the northern Yamato Basin of the Japan Sea by the JOIDES Resolution during Ocean Drilling Program (ODP) Leg 128 (Ingle, Suyehiro, von Breymann, et al., 1990). At this time, nine OBS's were also deployed around Hole 794D 


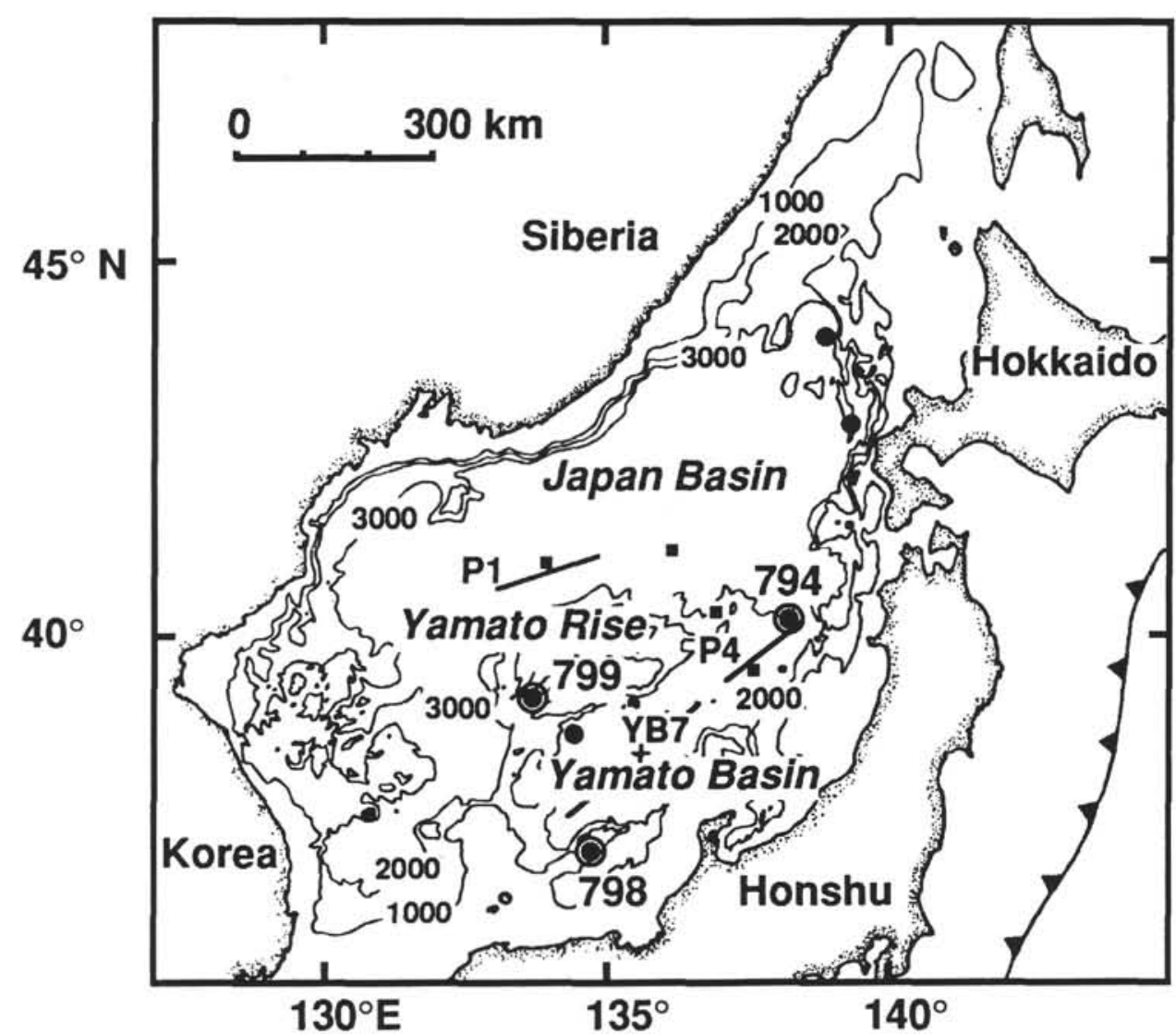

Figure 1. Map showing locations of drill holes in the Japan Sea (Ingle, Suyehiro, von Breymann, et al., 1990). Contour interval is $1,000 \mathrm{~m}$. Double circles denote holes drilled by Leg 128, ODP (Sites $794,798,799$ ). The OBDS was installed at Hole 794D. Circles and squares denote holes drilled by Leg 127, ODP, and Leg 31, DSDP, respectively. P1 and P4 are two ship refraction experiment lines reported by Murauchi (1972). YB7 shows location of an OBS deployed in 1985 reflection and refraction seismic experiment (Hirata et al. 1987).

(Fig. 1). A controlled source seismic refraction/reflection experiment using air guns, the OBDS, OBS's, and a hydrophone streamer was carried out with the support of the Tansei-maru, Ocean Research Institute (ORI), the University of Tokyo, to obtain a high-resolution seismic crustal structure in the northern Yamato Basin. In the present paper we report the detailed analysis of the crustal structure near Site 794 and focus on vertical and lateral heterogeneity of the crust.

\section{EXPERIMENTAL CONFIGURATION}

\section{Observation System}

\section{OBDS System}

The OBDS was installed on September 26, 1989. Hole 794D is $734 \mathrm{~m}$ below the seafloor (mbsf) at a water depth that is $2807 \mathrm{~m}$ below sea surface. A sedimentary section of Hole 794D was cased through $560 \mathrm{mbsf}$. The seismometer was clamped at $715 \mathrm{mbsf}$ in a hard igneous rock section. Real-time recording of digital data from the three-component feed-back-type accelerometer was performed aboard the JOIDES Resolution with time calibrated against Japan Standard Time by the radio signal JJY. A detailed description of the OBDS system is reported by Suyehiro et al. (this volume).

\section{OBS System}

Two types of OBS's, both of which are free-fall and transponder triggered pop-up types, were used in this study. One type of OBS was developed at the Geophysical Institute of the University of Tokyo, in cooperation with the Laboratory for Ocean Bottom Seismology, Hokkaido University (Yamada, 1980; Kanazawa, 1986). The other type was developed at Department of Earth Sciences, Chiba University, from the University of Tokyo type OBS (Matsuda et al., 1986), and contains a hydrophone channel.

Three-component velocity sensors with a natural frequency of $4.5 \mathrm{~Hz}$ are held by a gimbal mechanism. Signals are recorded on audio cassette tape by the direct analog recording (DAR) method. Because of the stability of the recording mechanism and a small temperature variation at the deep seafloor, the accuracy of timing in recording throughout the observation period is estimated to be less than $0.05 \mathrm{~s}$. All the analog data of OBS's were digitally processed on shore after the cruise (Urabe and Hirata, 1984).

\section{Digital Single-channel Reflection Experiment System}

Air-gun signals were also recorded by a digital single-channel hydrophone streamer towed by the Tansei-maru (Shinohara et al., 1989). The structure of the sedimentary layers was determined precisely from reflection records with a large dynamic range. As the acoustic basement is rugged, the high dynamic range also serves to enhance the resolution of the deeper structure.

\section{Positioning}

Ship positioning of the Tansei-maru, which acted as the shooting vessel, was accomplished using the Global Positioning System (GPS) and Loran-C. A detailed discussion of navigation accuracy can be 
found in Hirata et al. (this volume). Here, we describe the outline. The positioning data from the navigation system were stored on a microcomputer every 4-15 s. Scatter in position data indicates that the accuracies of the GPS and the Loran-C are about $20 \mathrm{~m}$ and $200 \mathrm{~m}$, respectively. First, we determined the positions where the air guns were shot, by interpolation of GPS data, where available. The positions determined by Loran-C data were found to be a linear translation of GPS data. Hence, when GPS data were not available, the positions determined by Loran- $\mathrm{C}$ were used with appropriate corrections. The accuracy of all the positions is estimated to be about $20 \mathrm{~m}$.

Because the OBS's are a free-fall type, positions of the OBS's at the deep seafloor may differ from their launching positions. Therefore, the positions of the OBS on the seafloor were relocated using the traveltimes of direct water waves within $10 \mathrm{~km}$ of the OBS. Typically, 200 of direct-wave traveltimes were used for each OBS relocation. The estimated accuracy of the instrument location is about $150 \mathrm{~m}$, which is comparable to a wavelength of the direct water wave.

\section{Real-time Experiment (RTE)}

Nine OBS's were deployed to obtain seismic records from the air guns (Fig. 2). One OBS launched near the OBDS recorded digital data for $9 \mathrm{hr}$, and the others recorded analog data for about 2 weeks. All the OBS's were successfully retrieved after the RTE. Regrettably, the digital-type OBS suffered from hardware trouble and recorded no seismic data. A three-dimensional (3-D) sub-array was formed by five closely spaced $(2800 \mathrm{~m})$ OBS's and the OBDS. The locations and the periods of observation for all OBS's are listed in Table 1.

The air-gun shooting profiles for the controlled source seismic experiment consisted of two concentric circles and two cross lines. Radii of the two circle profiles are $9 \mathrm{~km}$ (Inner Circle) and $18 \mathrm{~km}$ (Outer Circle). The east-west trending line (Line EW) is $90 \mathrm{~km}$ long, the other north-south line (Line NS) perpendicular to Line EW is $70 \mathrm{~km}$ long. The center of the circles and also the cross point of the two lines is the position of the OBDS. Air guns were shot every $60 \mathrm{~s}$ at $10 \mathrm{MPa}$ by either two $9-\mathrm{L}$ or a single $17-\mathrm{L}$ air gun (Table 2 ). The spacing between successive air gun shots was about $150 \mathrm{~m}$. During the 48-hr time period of shooting, data were recorded continuously by the OBDS. In this paper, we use records from four OBS's (JRT1, $4,5,8)$ and the OBDS to determine the seismic $P$-wave velocity structure along the two linear lines (Line EW, NS).

\section{DATA}

\section{Records of Digital Single-Channel (DSC) Reflection System}

The single-channel digital reflection records were band-pass filtered $(30-100 \mathrm{~Hz})$ and each trace shown was normalized by its maximum amplitude to enhance reflection signals.

\section{Line EW (Fig. 3)}

The seafloor is deeper around the position of the OBDS, and shows morphologically high relief at the positions of JRT1 and JRT5. The thickness of the sedimentary layer at the OBDS is about $0.8 \mathrm{~s}$ in two-way traveltime. The acoustic basement shows morphologically high relief resembling a knoll at $13 \mathrm{~km}$ to the east and $22 \mathrm{~km}$ to the west of the OBDS.

\section{Line NS (Fig. 4)}

The seafloor deepens northward from $15 \mathrm{~km}$ south of the OBDS, where morphologically high relief is seen. The thickness of the sedimentary layer is almost constant in the northward section of the OBDS. The acoustic basement also shows morphologically high relief $15 \mathrm{~km}$ south of the OBDS.

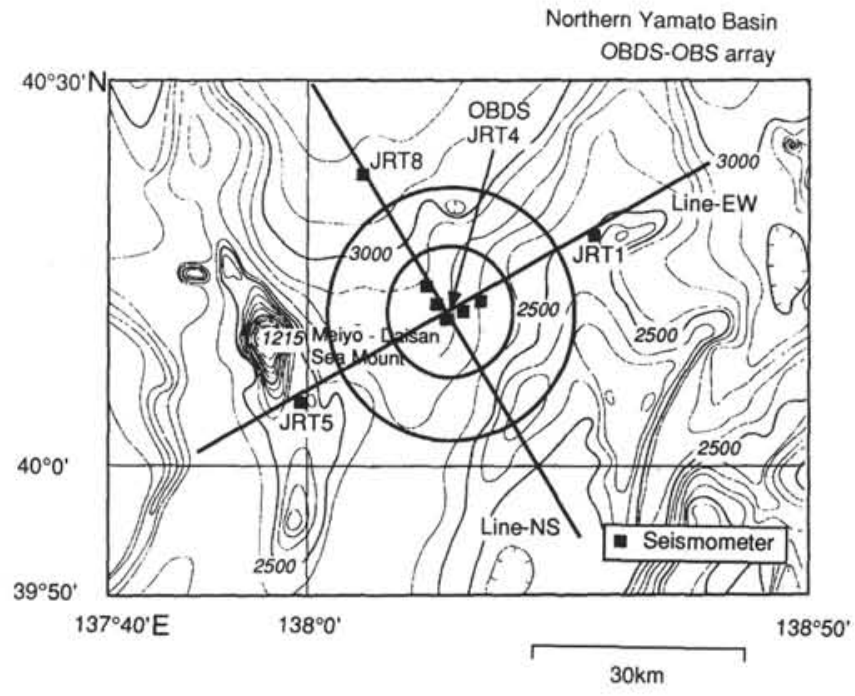

Figure 2. Local bathymetry surrounding ODP Hole 794D and locations of the OBDS and nine OBS's. Contour interval is $100 \mathrm{~m}$. Five OBS's spaced closely every $2800 \mathrm{~m}$, and the OBDS formed a 3-D sub-array. The digital-type OBS was deployed at the same position as JRT4. Air-gun profiles (solid line) consist of two concentric circles and two perpendicular lines.

\section{Records of the Seismometers}

We will discuss seismograms recorded on the high-gain, verticalcomponent geophone. The band-pass frequency is from 5 to $15 \mathrm{~Hz}$. Each trace shown is normalized by its maximum amplitude. The distance is measured from the position of the OBDS which is nearly at the center of the profiles. All of the seismometer records for Line NS have generally higher signal-to-noise ratios than the records for Line EW due to better weather conditions.

\section{Line EW}

\section{OBDS (Fig. 5)}

Between the ranges of 2 and $6 \mathrm{~km}$ east of the OBDS, the first-arrival phase has an apparent velocity of $4.3 \mathrm{~km} / \mathrm{s}$. At offset distances greater than $30 \mathrm{~km}$, the apparent velocity of the first arrivals is $7.2 \mathrm{~km} / \mathrm{s}$. The small amplitudes of the first arrivals at $10 \mathrm{~km}$ are attributed to a knoll. We have no data from 6 to $10 \mathrm{~km}$ because of a technical problem. In the western section, the apparent velocity of the first arrivals is $3.8 \mathrm{~km} / \mathrm{s}$ at offset distances from 1 to $5 \mathrm{~km} ; 5.0 \mathrm{~km} / \mathrm{s}$ at offset distances from 5 to $13 \mathrm{~km}$; and $7.1 \mathrm{~km} / \mathrm{s}$ at offset distances greater than $13 \mathrm{~km}$. A triplication is seen at a distance of $10 \mathrm{~km}$. The first arrivals are seen up to $40 \mathrm{~km}$ west of the OBDS.

\section{JRT4 (Fig. 6)}

JRT4 is the OBS just above the OBDS. In the east section, the apparent velocity for the first arrivals is $4.3 \mathrm{~km} / \mathrm{s}$ at offset distances less than $7 \mathrm{~km}$ and $6.4 \mathrm{~km} / \mathrm{s}$ at offset distances greater than $7 \mathrm{~km}$. In the west section, an apparent velocity for the first arrivals is $4.7 \mathrm{~km} / \mathrm{s}$ at distances less than $12 \mathrm{~km}$ and $6.3 \mathrm{~km} / \mathrm{s}$ at offset distances greater than $12 \mathrm{~km}$. The first arrivals are seen up to $27 \mathrm{~km}$ east of the OBS and $25 \mathrm{~km}$ west of the OBS. The small amplitude of the first arrivals at distances from 9 to $13 \mathrm{~km}$ east of JRT4 result from a knoll.

\section{JRTI (Fig. 7)}

JRT1 was located at about $25 \mathrm{~km}$ east of the OBDS. On the western side of JRT1, the apparent velocity of the first arrivals is $4.4 \mathrm{~km} / \mathrm{s}$ at offset distances less than $12 \mathrm{~km}$ and $5.9 \mathrm{~km} / \mathrm{s}$ at offset distances greater 
Table 1. Locations of OBS's and the OBDS and period of observation (Japan standard time).

\begin{tabular}{|c|c|c|c|c|c|c|c|}
\hline \multirow{3}{*}{$\begin{array}{l}\text { OBS } \\
\text { Code }\end{array}$} & \multirow{2}{*}{\multicolumn{2}{|c|}{ Latitude (N) }} & \multirow{2}{*}{\multicolumn{2}{|c|}{ Longitude (E) }} & \multirow{3}{*}{$\begin{array}{c}\text { Depth } \\
\text { (m) }\end{array}$} & \multicolumn{2}{|c|}{ Observation period } \\
\hline & & & & & & \multirow{2}{*}{$\begin{array}{c}\text { Deployment } \\
\text { Sept. } 1989\end{array}$} & \multirow{2}{*}{$\begin{array}{r}\text { Retrieval } \\
\text { Sept. } 1989\end{array}$} \\
\hline & Deg. & Min. & Deg. & Min. & & & \\
\hline JRTI & 40 & 18.07 & 138 & 28.72 & 2419 & $24,23: 52$ & $30,15: 11$ \\
\hline JRT2 & 40 & 13.04 & 1.38 & 17.24 & 2841 & $25,01: 03$ & $30,13: 20$ \\
\hline JRT3 & 40 & 12.34 & 138 & 15.75 & 2820 & $25,01: 29$ & $30,11: 09$ \\
\hline JRT4 & 40 & 11.37 & 138 & 14.03 & 2881 & $25,02: 11$ & $30,09: 56$ \\
\hline aJRT4H & & $b$ & & & & $25,02: 14$ & c \\
\hline JRT5 & 40 & 4.88 & 137 & 59.59 & 2440 & $25,06: 33$ & $29.16: 55$ \\
\hline JRT6 & 40 & 12.63 & 1.38 & 12.63 & 2908 & $25.02: 49$ & $30,09: 16$ \\
\hline JRT7 & 40 & 14.02 & 138 & 11.91 & 2931 & $25,03: 19$ & $30.07: 30$ \\
\hline JRT8 & 40 & 22.94 & 138 & 5.59 & 3213 & $25,04: 37$ & 29. $20: 07$ \\
\hline OBDS & 40 & 11.17 & 138 & 14.13 & 3533 & & \\
\hline
\end{tabular}

"A digital recording OBS.

bo positioning due to no signal record.

${ }^{\mathrm{C}}$ No time record of retrieval.

Table 2. Shooting periods and total number of shots in the refraction/reflection experiment (Japan standard time).

\begin{tabular}{cccc}
\hline Line & $\begin{array}{c}\text { Time start shooting } \\
\text { Sept. 1989 }\end{array}$ & $\begin{array}{c}\text { Time end shooting } \\
\text { Sept. 1989 }\end{array}$ & Total number of shots \\
\hline Inner circle & $27,07: 36: 05$ & $27,13: 52: 05$ & 377 \\
Outer circle & $27,15: 13: 05$ & $28,03: 45: 05$ & 596 \\
Line-EW & $28,06: 00: 05$ & $28,15: 30: 05$ & 571 \\
Line-NS & $28,23: 17: 55$ & $29,05: 35: 55$ & 379 \\
\hline
\end{tabular}

than $12 \mathrm{~km}$. A triplication is seen at an offset distance of $10 \mathrm{~km}$. The first arrivals are seen up to $40 \mathrm{~km}$ to the east of JRT1. On the eastern side of JRT1, the apparent velocity of the first arrivals is $5.0 \mathrm{~km} / \mathrm{s}$ out to the end of the profile at $19 \mathrm{~km}$.

\section{JRT5 (Fig. 8)}

JRT5 was located at about $25 \mathrm{~km}$ west of the OBDS. On the eastern side of JRT5, the apparent velocity of the first arrivals is $3.6 \mathrm{~km} / \mathrm{s}$ at offset distances less than $9 \mathrm{~km}$ and $6.4 \mathrm{~km} / \mathrm{s}$ at offset distances greater than $9 \mathrm{~km}$. A triplication is also seen at an offset distance of $10 \mathrm{~km}$. The first arrivals are seen up to $25 \mathrm{~km}$ to the west of JRT5. On the western side of JRT5, the apparent velocity of the first arrivals is $3.7 \mathrm{~km} / \mathrm{s}$ at offset distances less than $11 \mathrm{~km}$ and $5.5 \mathrm{~km} / \mathrm{s}$ out to the end of the profile at $19 \mathrm{~km}$.

\section{Line NS}

\section{OBDS (Fig. 9)}

In the southern section, the apparent velocity of the first arrivals is $5.0 \mathrm{~km} / \mathrm{s}$ at offset distances less than $9 \mathrm{~km}$ and $5.8 \mathrm{~km} / \mathrm{s}$ at offset distances greater than $8 \mathrm{~km}$. The first arrivals are seen out to the end of the profile $(37 \mathrm{~km})$. Small amplitudes for the first arrivals are seen at offset distances from 8 to $17 \mathrm{~km}$ due to a knoll. In the northern section, the apparent velocity of the first arrivals is $3.4 \mathrm{~km} / \mathrm{s}$ at offset distances less than $10 \mathrm{~km}$ and $7.5 \mathrm{~km} / \mathrm{s}$ at offset distances greater than $10 \mathrm{~km}$. A triplication is clearly seen at an offset distance of $10 \mathrm{~km}$. Refracted arrivals from the crust are seen out to the end of the profile $(36 \mathrm{~km})$.

\section{JRT4 (Fig. 10)}

In the southern section, the apparent velocity of the first arrivals is $5.0 \mathrm{~km} / \mathrm{s}$ at offset distances from 4 to $10 \mathrm{~km}$ and $6.3 \mathrm{~km} / \mathrm{s}$ at offset distances greater than $18 \mathrm{~km}$. Small amplitudes for the first arrivals due to a knoll are also seen at offset distances from 10 to $18 \mathrm{~km}$. The first arrivals are seen at up to an offset distance of $30 \mathrm{~km}$. In the northern section, the apparent velocity of the first arrivals is $4.3 \mathrm{~km} / \mathrm{s}$ at offset distances less than $13 \mathrm{~km}$ and $6.7 \mathrm{~km} / \mathrm{s}$ at offset distances greater than $13 \mathrm{~km}$. A triplication is also seen at an offset distance of $10 \mathrm{~km}$. The first arrivals are seen out to an offset distance of $30 \mathrm{~km}$.

\section{JRT8 (Fig. 11)}

JRT8 was located at $25 \mathrm{~km}$ south of the OBDS. In the southern side of JRT8, the apparent velocity of the first arrivals is $4.1 \mathrm{~km} / \mathrm{s}$ at short offset distances, $5.5 \mathrm{~km} / \mathrm{s}$ at offset distances from 9 to $14 \mathrm{~km}$, and $7.2 \mathrm{~km} / \mathrm{s}$ at offset distances greater than $14 \mathrm{~km}$. First arrivals are seen out to an offset distance of $35 \mathrm{~km}$. A triplication is also seen at an offset distance of $10 \mathrm{~km}$. A later phase that seems to be the reflected arrival from the lower crust with an apparent velocity of about 8.0 $\mathrm{km} / \mathrm{s}$, is seen at offset distances greater than $45 \mathrm{~km}$. On the northern side of JRT8, the apparent velocity of the first arrivals is $4.8 \mathrm{~km} / \mathrm{s}$.

\section{Comparison Between the OBS Records and the OBDS Records}

The differences between the records of the OBS's and those of the OBDS are as follows:

1. The data recorded by the OBDS have better signal-to-noise ratios than those recorded by the OBS. Therefore, refracted arrivals on the OBDS can be seen out to greater distances than on the OBS.

2 . The apparent velocity of the direct wave recorded by the OBDS is about $3.0 \mathrm{~km} / \mathrm{s}$ far from the OBDS. The direct wave is defined as the wave that propagates through the media above the receiver, which in this case includes the sediment layer.

3. Because the velocity gradient of the sedimentary layer is larger than that of water, the range in which the OBDS records the direct waves is narrow.

4. There are no coda waves after the direct-wave arrivals in the records of the OBDS.

5. Converted S-waves are clearly seen in the records of the OBDS (Fig. 12). Comparison of the horizontal component records reveals that $P$-wave arrivals are also clearly seen on the OBDS. These results are indicative of a strong mechanical interaction (coupling) between the OBDS and the ground, as compared to that between an OBS and the ground.

\section{ANALYSES AND RESULTS}

\section{One-dimensional Shallow Velocity Structure}

We derived one-dimensional (1-D) velocity structures beneath each OBS from the individual records. First, the seismic wave field in $x$ - $t$ (distance-traveltime) domain on one side of the OBS, is transformed into the tau- $p$ (intercept time-ray parameter) domain (Diebold and Stoffa, 1981; Stoffa et al., 1981). To map seismic data in $x-t$ domain to the domain of tau- $p$, we performed a slowness stack or ray parameter stack for linear trajectories through the $x$ - $t$ data. Semblance was used instead of a slowness stack to suppress the spatial aliasing and to get good signal-to-noise ratios in tau- $p$ domain. Semblance has been used in detecting coherent arrivals across an array (Neidell and Taner, 1971). After seismic data were mapped to tau- $p$ domain, trajectories of refractions and wide-angle reflections are picked from the records. A $P$-wave velocity-depth function is then derived from the trajectory by the tau-sum inversion method (Diebold and Stoffa, 1981). Hereafter, we call this procedure the tau- $p$ method.

We used the low-gain vertical geophone component at distances from 0 to $10 \mathrm{~km}$ to derive the shallow structure and the high-gain vertical component at distances from 10 to $20 \mathrm{~km}$ to derive the deeper structure. In the tau- $p$ domain, this corresponds to trajectories where $p$ is greater than $0.2 \mathrm{~s} / \mathrm{km}$ on the low-gain component, and trajectories where $p$ less than $0.2 \mathrm{~s} / \mathrm{km}$ on the high-gain component. The picking errors of the trajectories are about $0.1 \mathrm{~s}$ in tau domain. This 


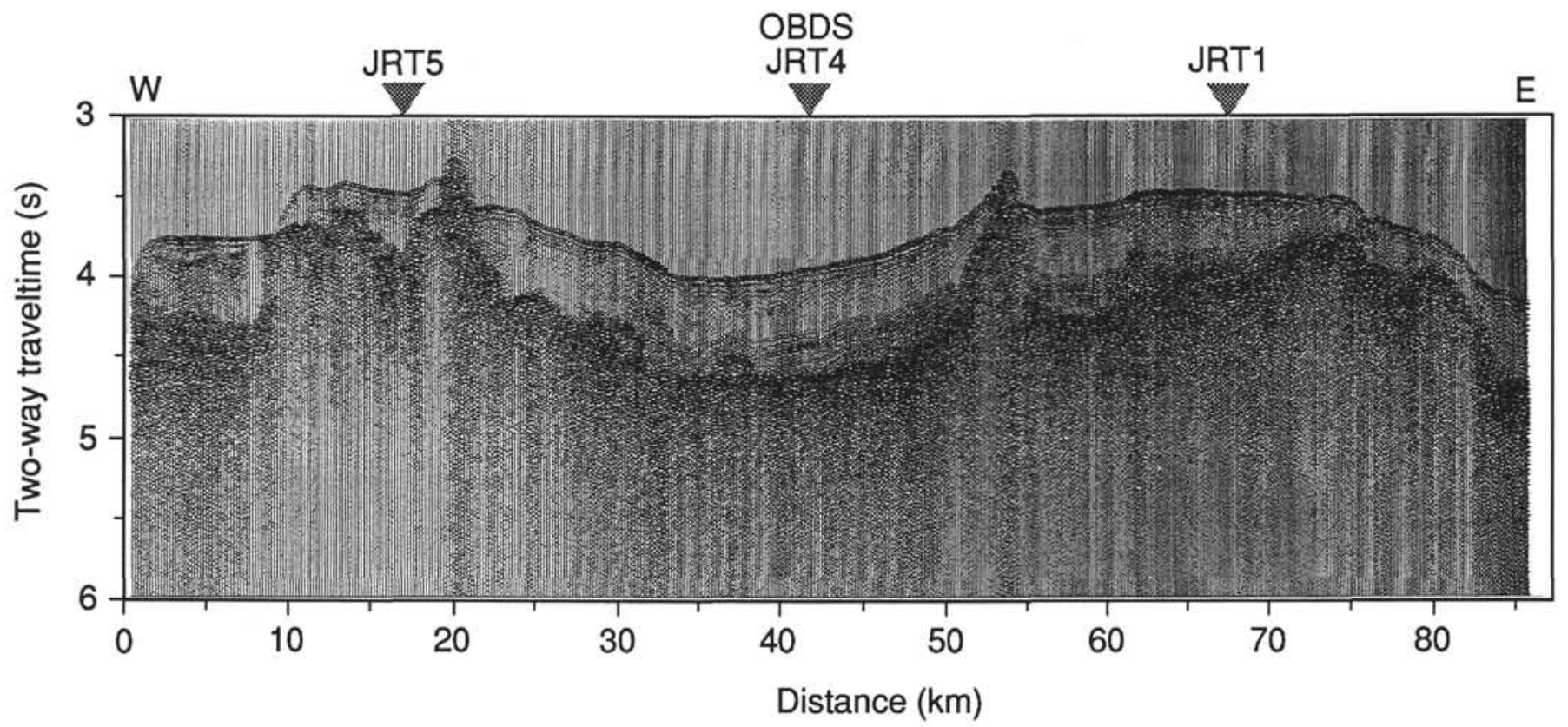

Figure 3. Digital single-channel seismic reflection record for Line EW obtained simultaneously with the refraction experiment. Distance along the profile is positive eastward. Band-pass filtering is 30-100 Hz. Each trace is normalized by its maximum amplitude. The positions of the OBDS and the OBS's (JRT1, JRT4, JRT5) are marked.

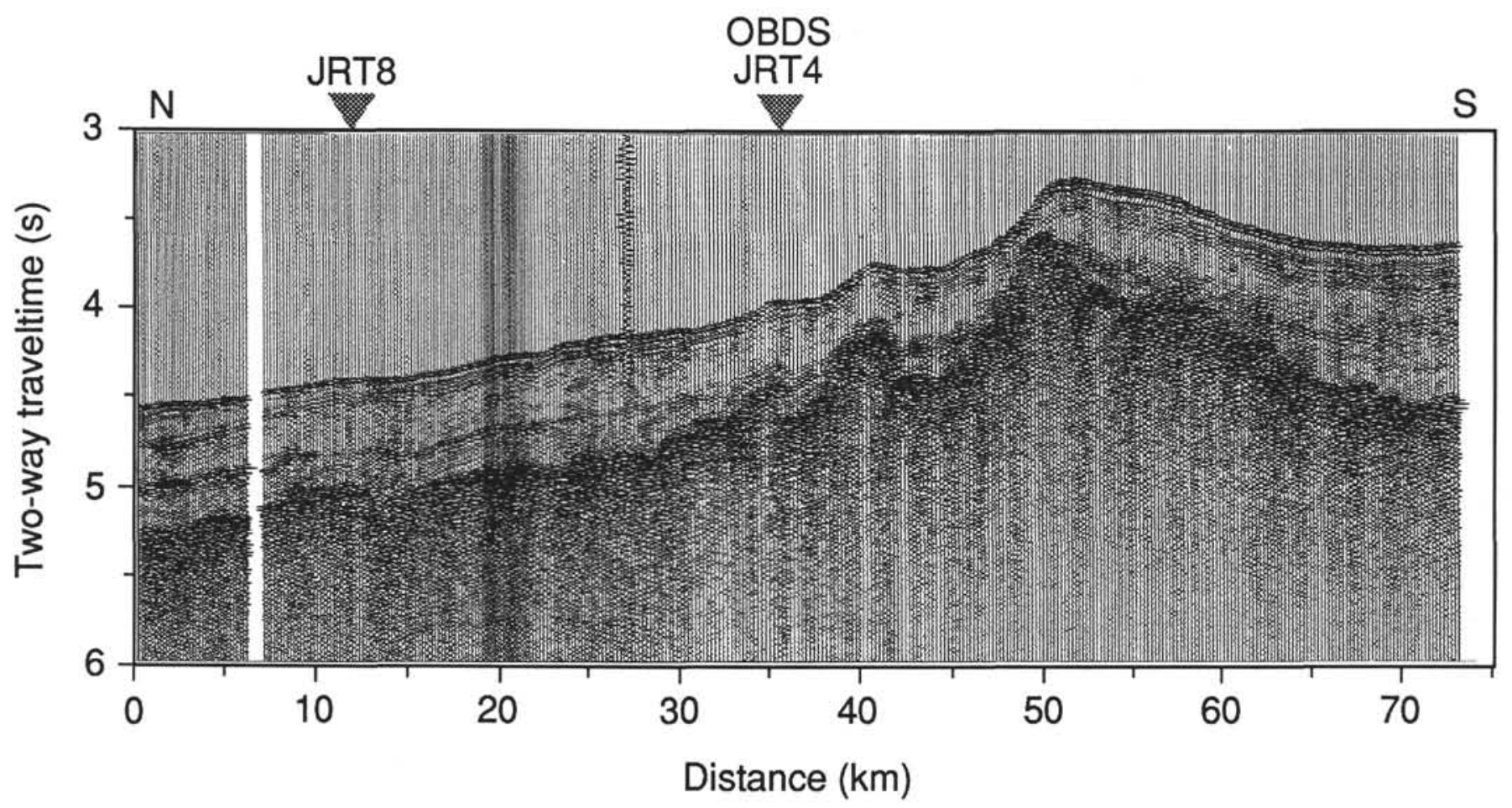

Figure 4. Digital single-channel seismic reflection record for Line NS. Distance is positive southward. The positions of the OBDS and the OBS's (JRT4, JRT8) are marked. See Figure 3 for detailed explanation. 
OBDS

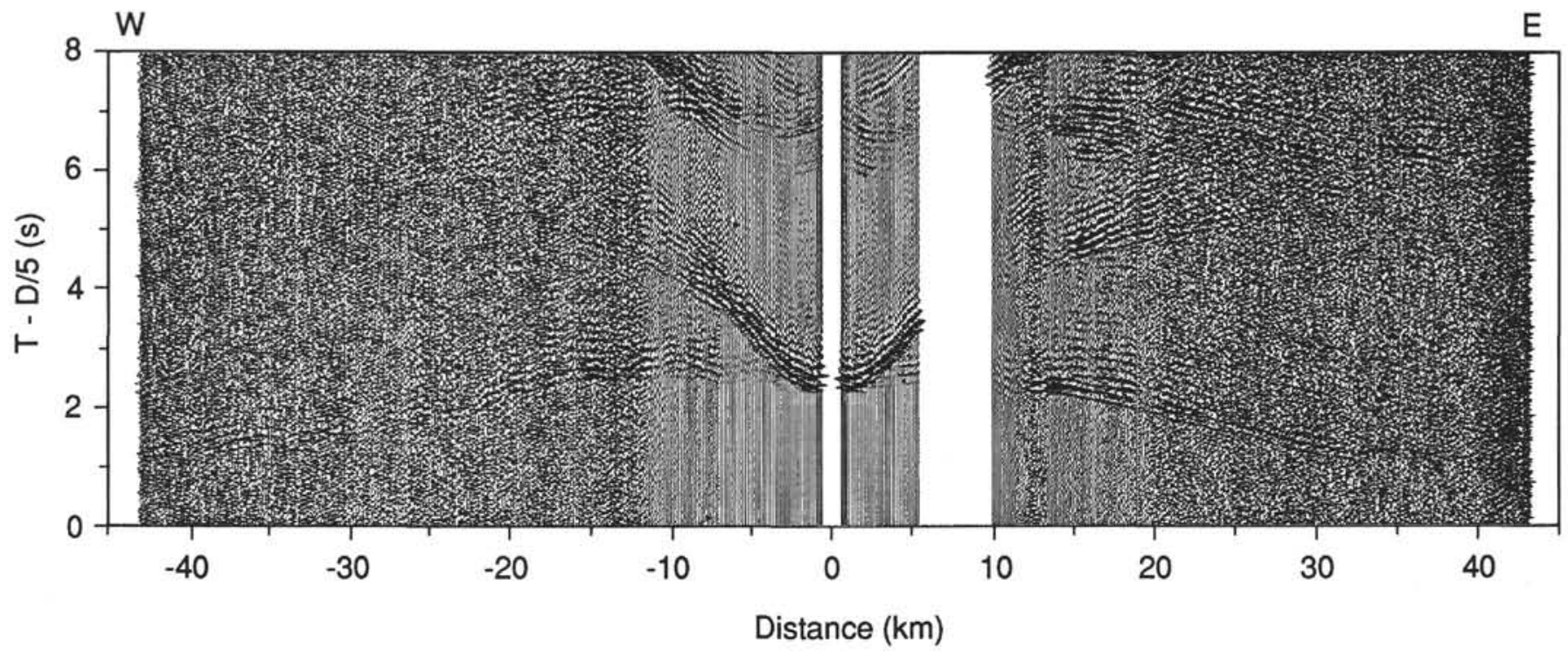

Figure 5. Record section for the vertical component, high-gain channel of the OBDS for Line EW. Reduction velocity is $5.0 \mathrm{~km} / \mathrm{s}$. Band-pass filtering is $5-15 \mathrm{~Hz}$. Each trace is normalized by its maximum amplitude. First arrivals are seen at greater distances on the OBDS than on the OBS's and no coda waves are observed after the direct waves on the OBDS.

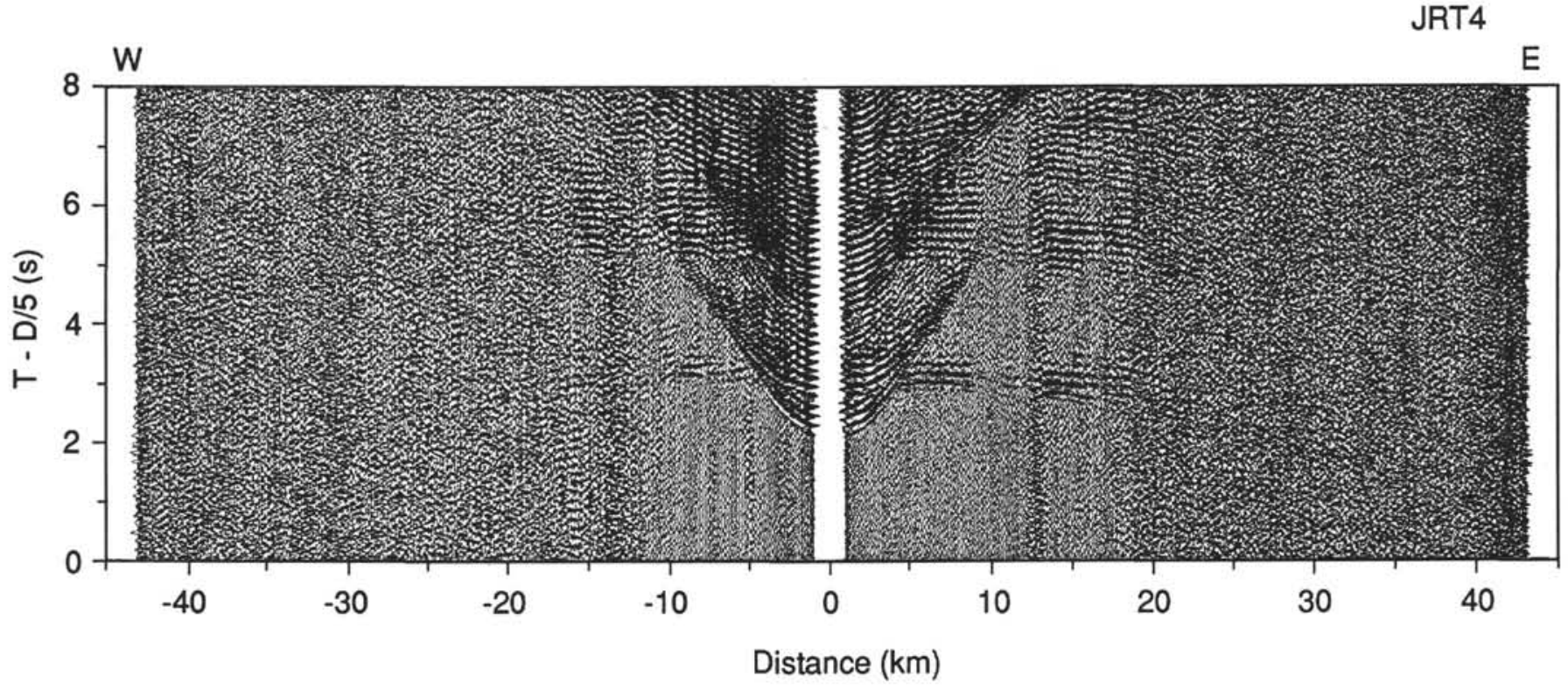

Figure 6. Record section of OBS JRT4 for Line EW. See Figure 5 for detailed explanation.

value of picking error is considered to correspond to a few hundred meters of depth.

The structure derived by the tau- $p$ method assumes horizontally homogeneous layers. We applied the tau- $p$ method to records on both sides of the OBS, thus resulting in two velocity-depth functions for each OBS profile. Differences in the two velocity-depth functions for each side were taken to represent lateral heterogeneity in the crust.

The 1-D velocity-depth functions were derived from records of four OBS's: JRT1, JRT4, JRT5, and JRT8 (Figs. 13 through 17). As an example, the velocity-depth functions are compared with the associated single-channel reflection profiling records in Figure 18. The velocity in the uppermost layer just below all OBS's is $1.7 \mathrm{~km} / \mathrm{s}$ with a small velocity gradient with depth. The $1.7 \mathrm{~km} / \mathrm{s}$ layer is about $700 \mathrm{~m}$ thick under JRT4, about $500 \mathrm{~m}$ under JRT1, about $300 \mathrm{~m}$ under JRT5, and $700 \mathrm{~m}$ under JRT8. The $1.7-\mathrm{km} / \mathrm{s}$ layer corresponds to the acoustic transparent sedimentary layer seen in the reflection records.

A layer with a $P$-wave velocity of about $4.5 \mathrm{~km} / \mathrm{s}$ underlies the sedimentary layer under JRT1, JRT4, and JRT8. The vertical gradient of velocity in the $4.5-\mathrm{km} / \mathrm{s}$ layer is about $0.25 \mathrm{~s}^{-1}$. The velocity of the uppermost part of the $4.5-\mathrm{km} / \mathrm{s}$ layer increases rapidly from 2.0 to $4.5 \mathrm{~km} / \mathrm{s}$ within the uppermost $300 \mathrm{~m}$. In the reflection records, the rapid increase in velocity corresponds to a clear reflector of the acoustic basement. The increase in velocity under JRT5, however, is different from others. The velocity just below the sedimentary layer 


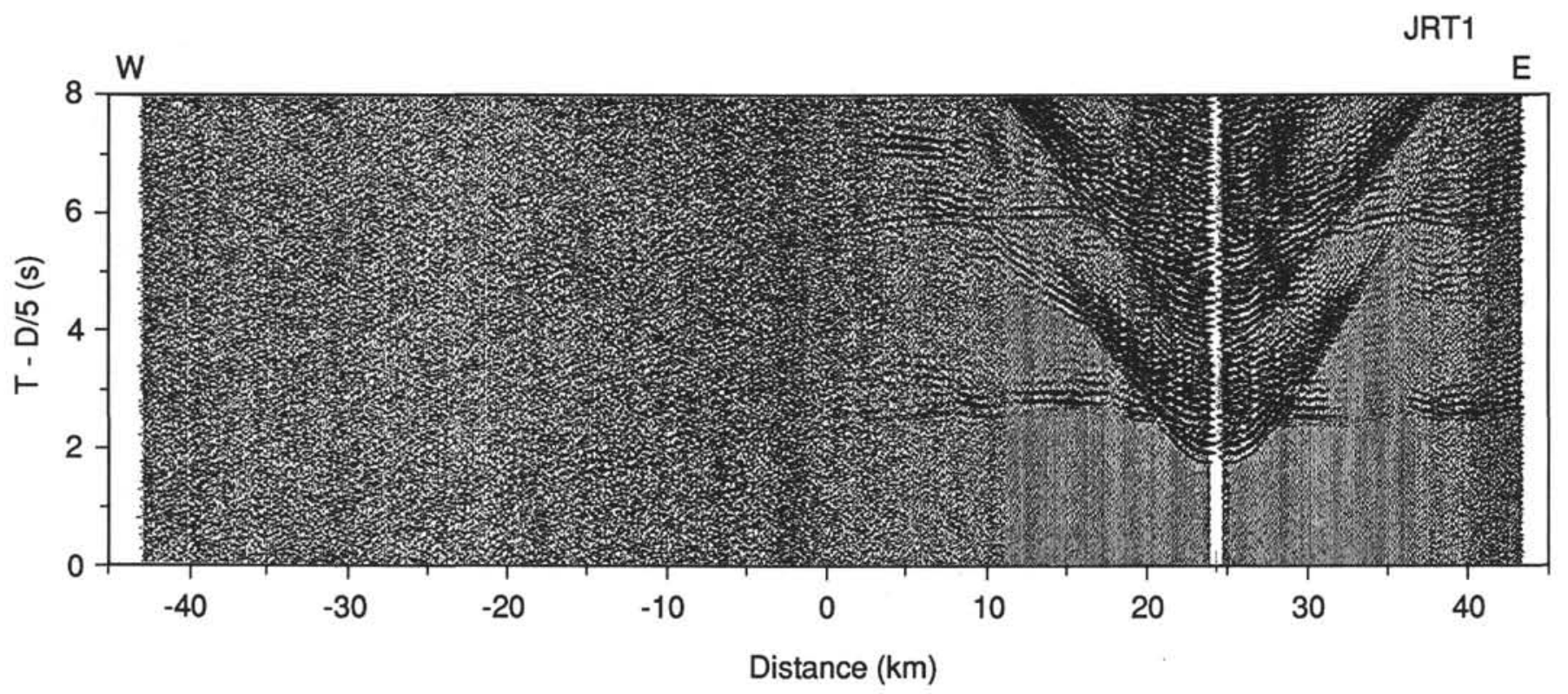

Figure 7. Record section of OBS JRT1 for Line EW. See Figure 5 for detailed explanation.

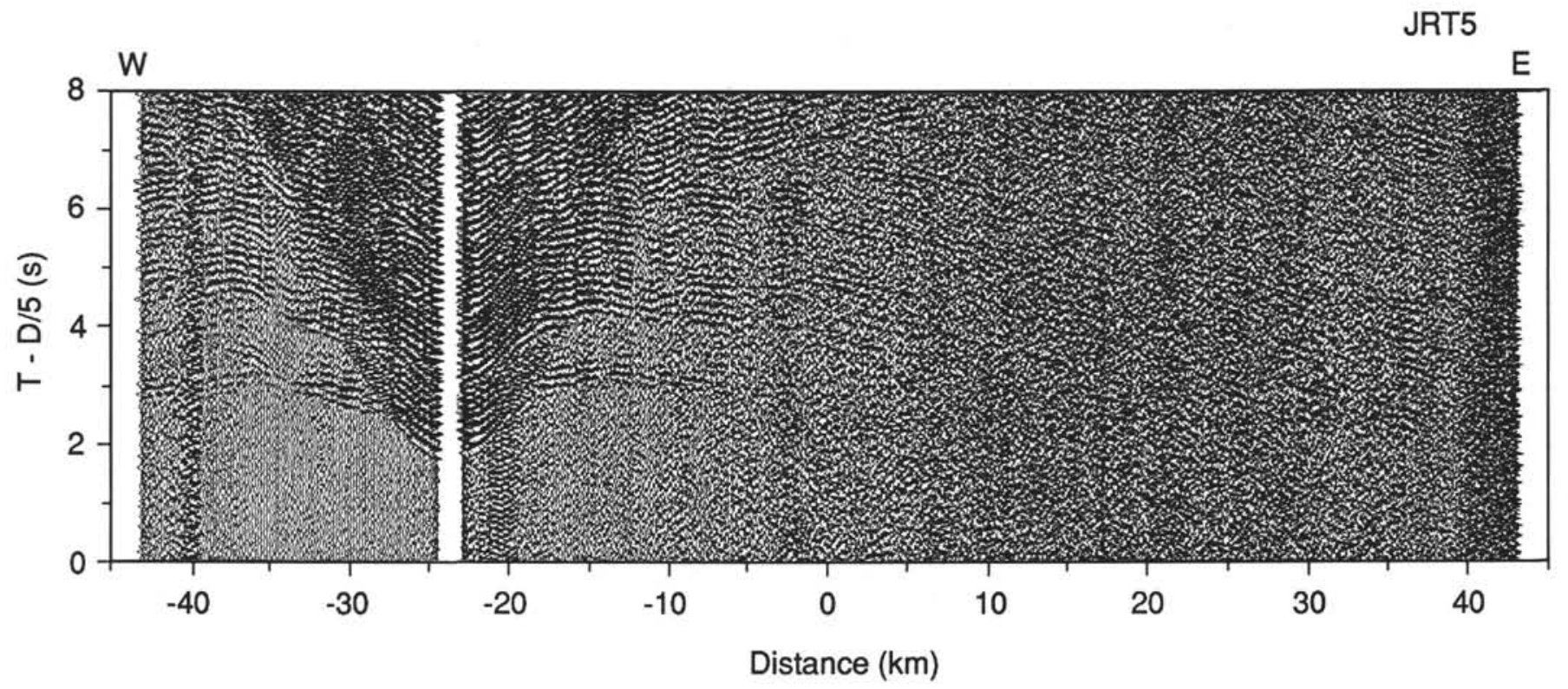

Figure 8. Record section of OBS JRT5 for Line EW. See Figure 5 for detailed explanation.

is $2.0 \mathrm{~km} / \mathrm{s}$ with a gradient of $5.0 \mathrm{~s}^{-1}$. The $4.5-\mathrm{km} / \mathrm{s}$ layer underlies the $2.0-\mathrm{km} / \mathrm{s}$ layer and is $1500 \mathrm{mbsf}$. The velocities and the velocity gradients in the $4.5-\mathrm{km} / \mathrm{s}$ layer are similar for all the OBS's.

\section{Two-dimensional Velocity Structure}

Two-dimensional (2-D) velocity structures along lines EW and NS were derived by 2-D ray tracing using first arrivals and later phases to derive shapes of velocity interfaces and velocities at deeper levels. The first refracted arrivals for all OBS's were picked from the records (Fig. 19). The apparent velocities of the first arrivals of all the OBS's is $6-7 \mathrm{~km} / \mathrm{s}$ at offset distances greater than $10 \mathrm{~km}$. An offset in traveltimes of the first refracted arrivals at $-10 \mathrm{~km}$ and $11 \mathrm{~km}$ range can be seen in the OBDS and all the OBS's data. The gap results from the morphologically high relief along the shooting line in the reflection experiment.
Trial-and-error forward modeling of the traveltimes was used to determine the velocity structure. Theoretical traveltimes were calculated by geometrical optics ray theory (Hirata and Shinjo, 1986; Červeńy and Pšencík, 1983). The initial 2-D model was constructed from 1-D models under individual OBS's. The sedimentary layer and the acoustic basement were derived from the reflection data. The final velocity structure (Fig. 20) was determined so that the difference between calculated and observed traveltimes was less than $0.2 \mathrm{~s}$; however, most calculated traveltimes fit with observed arrivals to within $0.1 \mathrm{~s}$. Our model can also explain the triplication seen at about $10-\mathrm{km}$ range on each seismometer.

\section{Line $\mathrm{EW}$}

The OBDS, JRT1, JRT4, and JRT5 were used to determine this model (Figs. 21-24). The 4.5-km/s layer, which is laterally heteroge- 


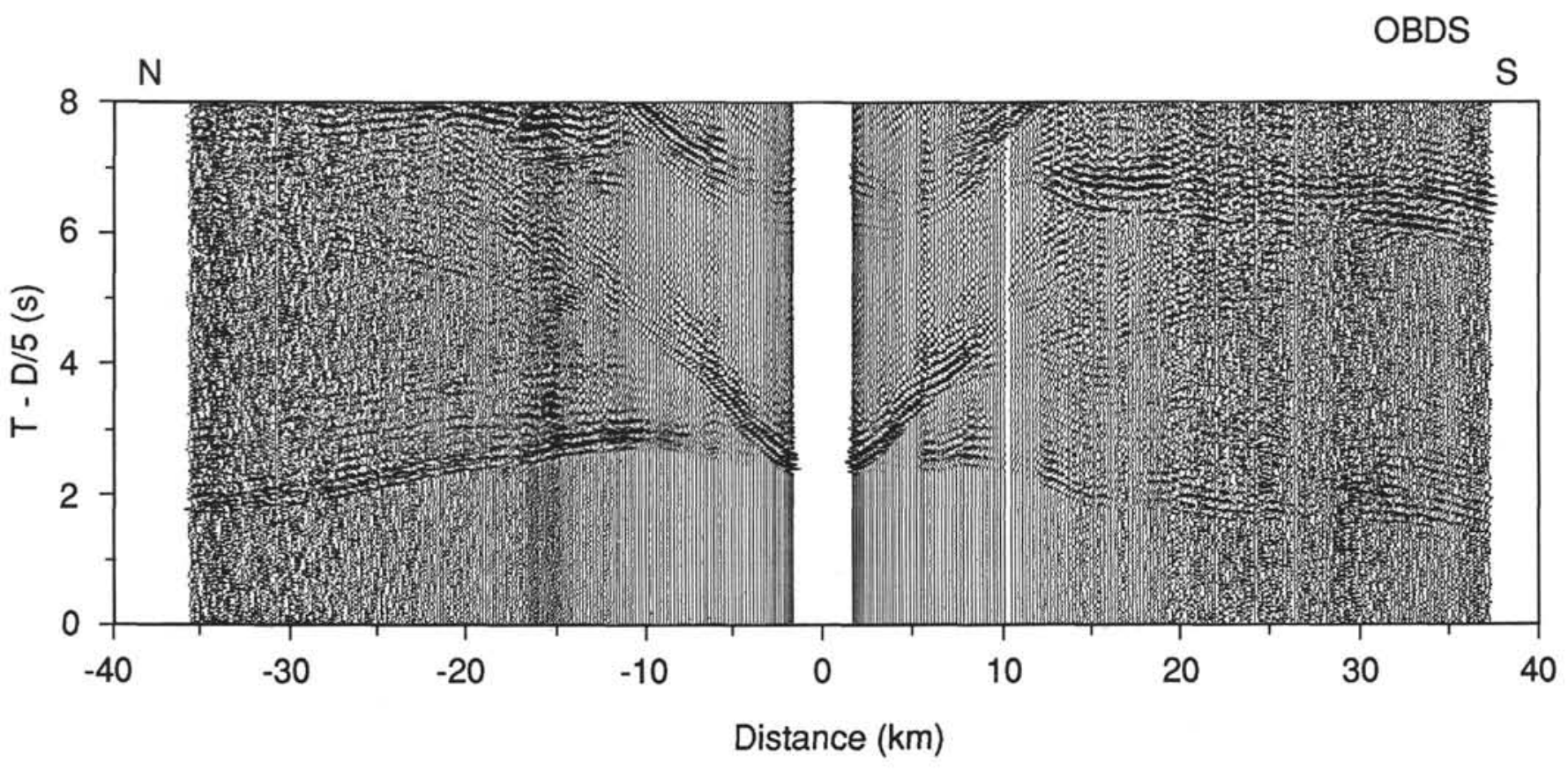

Figure 9. Record section of the OBDS for Line NS. See Figure 5 for detailed explanation.

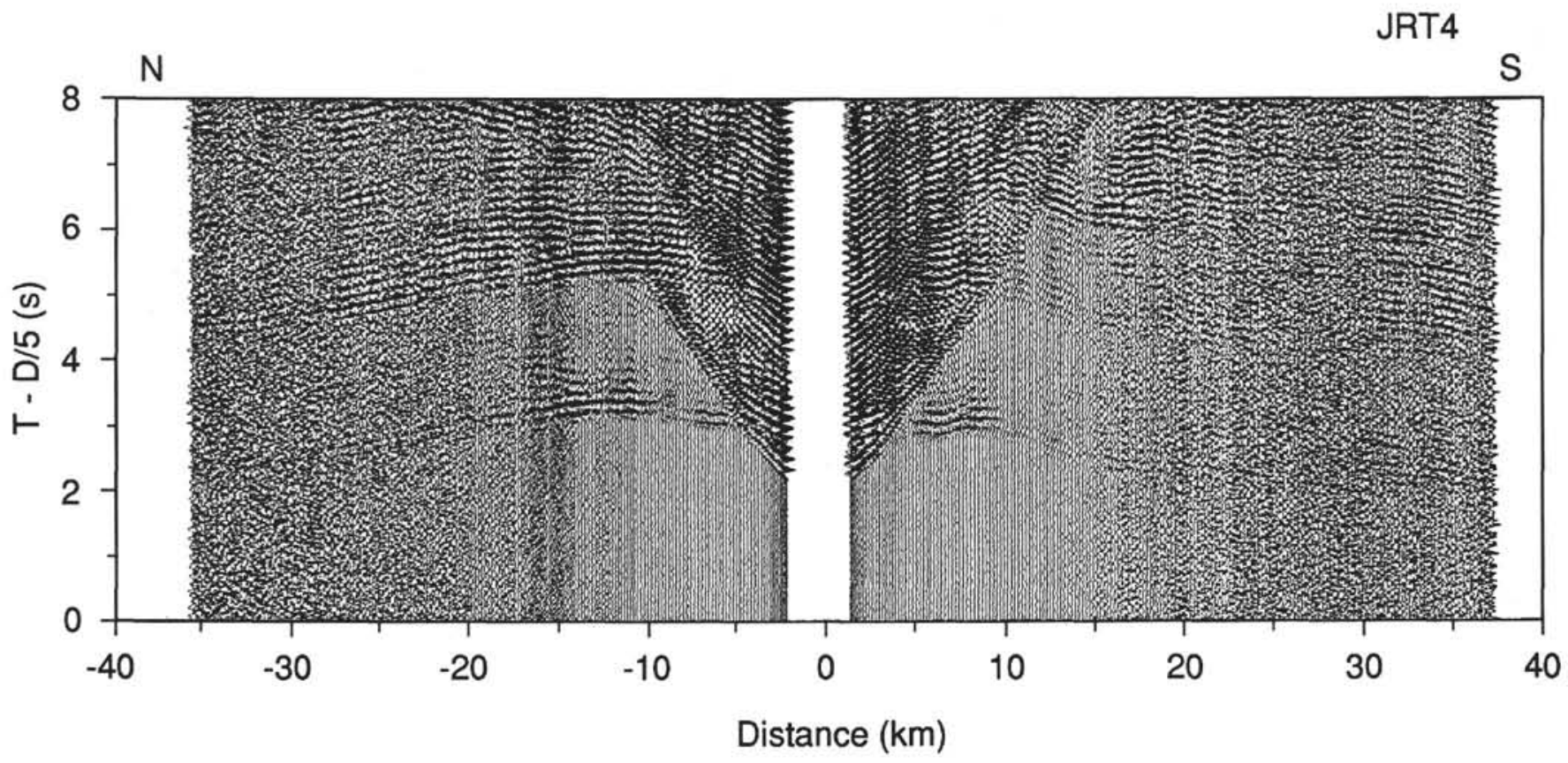

Figure 10. Record section of OBS JRT4 for Line NS. See Figure 5 for detailed explanation.

neous, is about $2 \mathrm{~km}$ thick along the profile. The $4.5-\mathrm{km} / \mathrm{s}$ layer is thin under JRT1 east of the profile and thick under JRT5 west of the profile. The velocity of the layer below the $4.5-\mathrm{km} / \mathrm{s}$ layer is estimated to be $6.2 \mathrm{~km} / \mathrm{s}$ base on the tau- $p$ method and the apparent velocities of the first arrivals on the OBS's. This model also predicts successfully the triplication at $10-\mathrm{km}$ distance on the OBDS and JRT4. Although the gradient of the $6.2-\mathrm{km} / \mathrm{s}$ layer could not be determined exactly, the gradient must be less than $0.2 \mathrm{~s}^{-1}$ because arrivals at offset distances greater than $25 \mathrm{~km}$ were observed on all seismometers. Because the OBDS observed arrivals with an apparent velocity of $6 \mathrm{~km} / \mathrm{s}$ up to 40 $\mathrm{km}$, it is inferred that the $6.2-\mathrm{km} / \mathrm{s}$ layer extends downward to at least $12-\mathrm{km}$ depth from the sea surface (i.e., thickness is more than $6 \mathrm{~km}$ ).
A layer with a $P$-wave velocity of $3.0 \mathrm{~km} / \mathrm{s}$ overlies the $4.5-\mathrm{km} / \mathrm{s}$ layer around JRT5. The $3.0-\mathrm{km} / \mathrm{s}$ layer is required to explain the traveltimes of refracted waves from the $4.5-\mathrm{km} / \mathrm{s}$ layer at distances less than $5 \mathrm{~km}$ on JRT5.

\section{Line NS}

The OBDS, JRT4, and JRT8 were used to determine this model (Figs. 25-27). Layer thicknesses were forced to coincide with those of Line EW under the OBDS where two lines crossed. Because the north section of Line NS on the OBDS is not reversed, this part of the model is not well constrained. The interface between the $4.5-\mathrm{km} / \mathrm{s}$ 


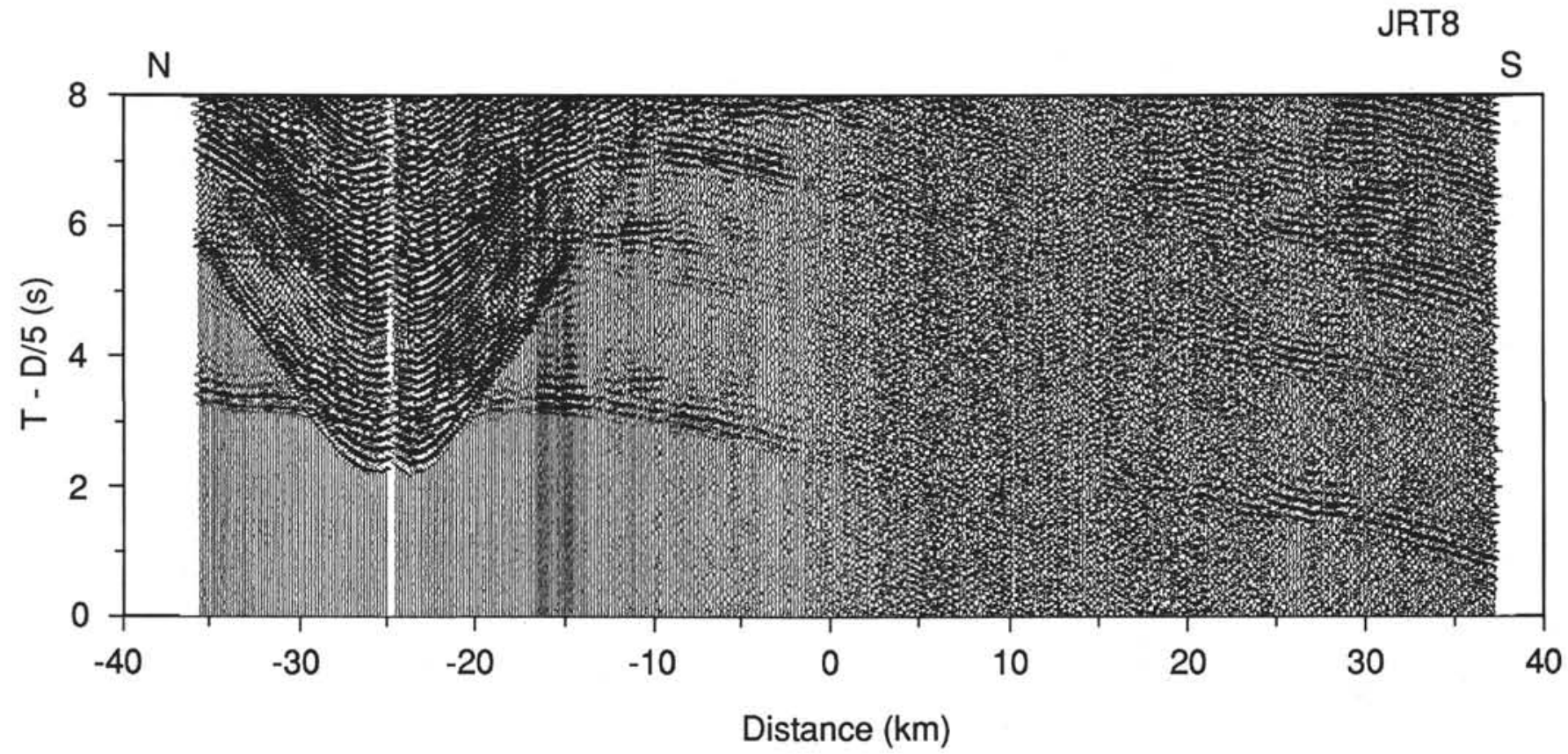

Figure 11. Record section of OBS JRT8 for Line NS. See Figure 5 for detailed explanation.

layer and the $6.2-\mathrm{km} / \mathrm{s}$ layer is shallower at the both ends of this profile. A model with a $4.5-\mathrm{km} / \mathrm{s}$ layer with a thickness of about $2 \mathrm{~km}$ and a $6.2-\mathrm{km} / \mathrm{s}$ layer can explain the triplication seen on all the seismometers. For the same reasons as in Line EW, the thickness of the $6.2-\mathrm{km} / \mathrm{s}$ layer is thought to be more than $6 \mathrm{~km}$. Because the later phase at offset distance greater than $45 \mathrm{~km}$ in the records of JRT8 is interpreted as a crust-mantle reflection $\left(P_{\mathrm{m}} P\right)$, the Moho is suggested to be about $16 \mathrm{~km}$ deep.

\section{DISCUSSION}

The structure obtained in the northern Yamato Basin can be compared with structures in other areas in the Japan Sea (Fig. 28). It is clear from our data that the northern Yamato Basin is different from the Japan Basin from crustal thickness alone. The crust in the Japan Basin is $8 \mathrm{~km}$ thick or less (Murauchi, 1972), whereas the data from the present study indicate no evidence of the oceanic crust. Although we did not detect refracted arrivals from the Moho, the reflection phase from the Moho $\left(P_{\mathrm{m}} P\right)$ indicates that the depth should be greater than that in the Japan Basin.

The southern Yamato Basin was studied previously using modern reflection and refraction techniques that included profile lines shot with an air gun and explosives to OBS's (Hirata et al., 1987, 1989; Katao, 1988; Chung et al., 1990). The crustal structure in the southern Yamato Basin is neither typical oceanic nor continental. As the OBS air-gun profiling method used in the survey is almost identical to that used in our experiment, it is worthwhile to compare directly both records. Figure 29 shows a comparison between data from JRT8 in the northern Yamato Basin and from YB7 (Fig. 1) in the southern Yamato Basin. We see a close resemblance between the two record sections over the first $25 \mathrm{~km}$ of range. Both crusts have a 1-km-thick sedimentary layer with a $P$-wave velocity from 2.0 to $3.0 \mathrm{~km} / \mathrm{s}$. A layer with a large velocity gradient underlies the sediments. The velocity in this layer increases from 3.0 to $5.2 \mathrm{~km} / \mathrm{s}$ near Hole 794D, and from 3.8 to $5.4 \mathrm{~km} / \mathrm{s}$ beneath YB7 in the southern Yamato Basin (Fig. 30). The Ludwig et al. (1975) findings of a thick sediment and an upper crust with a large velocity gradient in the northern Yamato Basin, using sonobuoy refraction data, also agree with our study.
The velocity structure from 7 to $12 \mathrm{~km}$ depth also is similar in both the southern and northern Yamato Basin; the vertical gradient is $0.1 \mathrm{~s}^{-1}$. We can not compare the lowermost crustal structure because no clear phases with reversed profiles are available in our data.

The total thickness of the crust can not be unambiguously determined from our data. It is, however, likely that the northern Yamato Basin has slightly thinner crust (about $16 \mathrm{~km}$ below sea surface) because the reflected arrival from the Moho $\left(P_{\mathrm{m}} P\right)$ at the JRT8 appears at a shorter offset range $(40 \mathrm{~km})$ than was observed on YB7 in the southern Yamato Basin $(45 \mathrm{~km})$. These results are consistent with those reported by Murauchi (1972) for profile P4 (Fig. 1) in the northern Yamato Basin. He found a 12-km-thick crust, (the Moho at a depth of $14 \mathrm{~km}$ below sea surface), indicating a thinner crust in the northern than in the southern Yamato Basin.

Thus, our observations and the previous studies indicate that the northern and southern Yamato Basin have a similar crustal structure as shown by the velocities and thicknesses of layers. The crustal structure of both the basins are characterized as possessing a sedimentary layer about $1 \mathrm{~km}$ thick that is thinner than in the Japan Basin (Ludwig et al., 1975), and an uppermost igneous crust with a large velocity gradient, previously not resolved.

Our detailed data analysis revealed that the velocity of the uppermost part of the $4.5-\mathrm{km} / \mathrm{s}$ layer increases rapidly from 2.0 to $4.5 \mathrm{~km} / \mathrm{s}$ over $300 \mathrm{~m}$ of thickness. As we observed many sills and flows in the sampled core at Sites 794 and 797, the shallowmost crust of the basement layer is interpreted to represent a sediment-sill complex, which is seismically imaged as a zone with large velocity gradient with depth.

Recently it has been suggested that the thickened crust found in the southern Yamato Basin formed because a large amount of igneous material was intruded into it after an oceanic crust formed (Hirata et al., 1989). Another interpretation is that the thick crust (about $14 \mathrm{~km}$ ) and the low velocity gradient of the $6.2-\mathrm{km} / \mathrm{s}$ layer may be considered to indicate that an oceanic crust never formed through backarc evolution, and that the thinning of a continental crust during the initial stage of rifting is responsible for the obtained structure. In this case, igneous material intrusion was not so great. At this stage we cannot discriminate the two models from our results. 


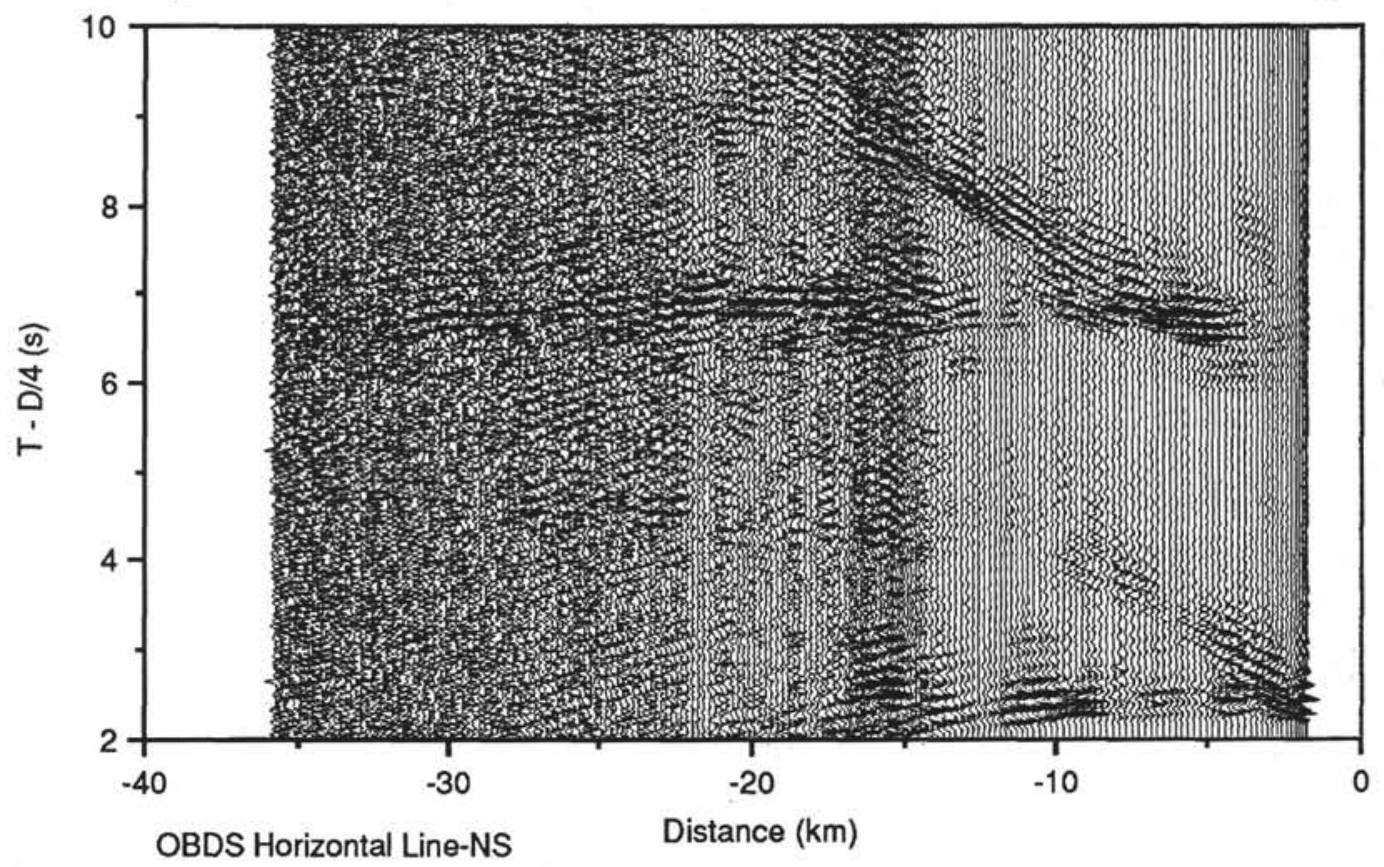

$\mathrm{N}$

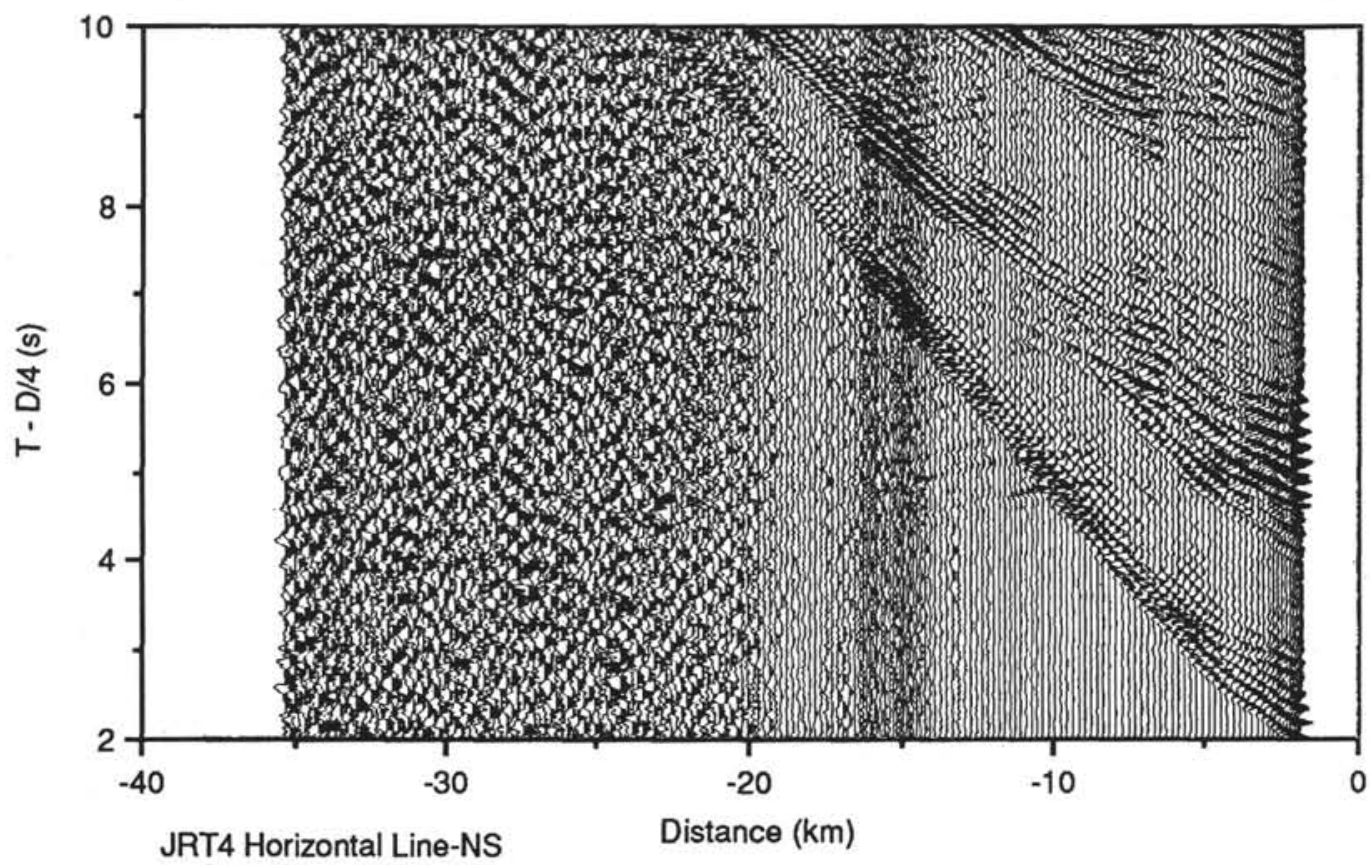

Figure 12. Comparison of the horizontal component record of the OBDS records to that of OBS (JRT4) just above the OBDS. Reduction velocity is $4.0 \mathrm{~km} / \mathrm{s}$. Band-pass filtering is $5-15 \mathrm{~Hz}$. Each trace is normalized by its maximum amplitude. Converted $S$-wave arrivals are seen in the records of the OBDS.

\section{CONCLUSIONS}

An ocean broadband downhole seismometer (OBDS) was installed in Hole 794D in the northern Yamato Basin of the Japan Sea as a part of Leg 128 in 1989. The digital signals of the OBDS were continuously recorded on JOIDES Resolution for about 60 $\mathrm{hr}$, which we call the real-time experiment. A seismic refraction/reflection experiment using air guns, the OBDS, and OBS's also was conducted during the real-time experiment. Nine OBS's were deployed surrounding Hole 794D. Five OBS's were deployed every $2800 \mathrm{~m}$ near Hole 794D, and the OBDS formed a 3-D sub array. The profiles consisted of two circles and two lines. Air guns were shot every $60 \mathrm{~s}$, i.e., $150 \mathrm{~m}$. The signals of the air guns were also recorded by a single hydrophone streamer. The seismic structure was derived from the data recorded by the OBDS and the four OBS's deployed every $25 \mathrm{~km}$. 


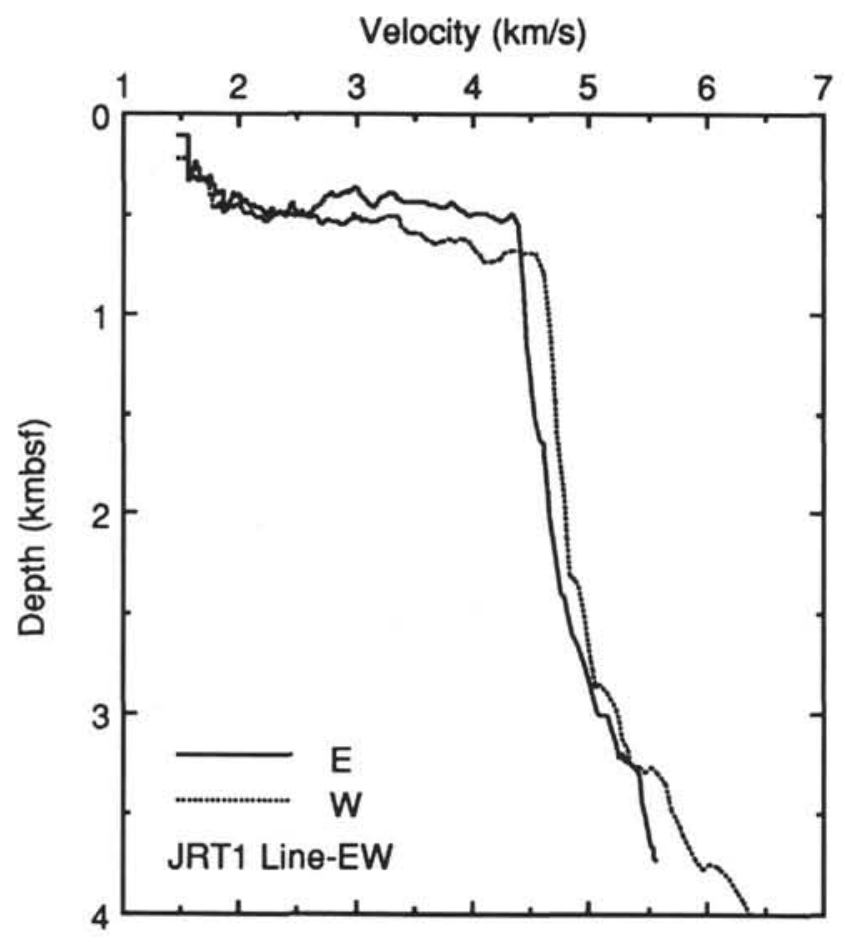

Figure 13. One-dimensional $P$-wave velocity models beneath OBS JRT1 obtained for each single-sided profile of Line EW by the tau- $p$ method. Solid and dash lines correspond to the models derived from the records of the eastward and westward shots, respectively. Depth is measured from the seafloor.

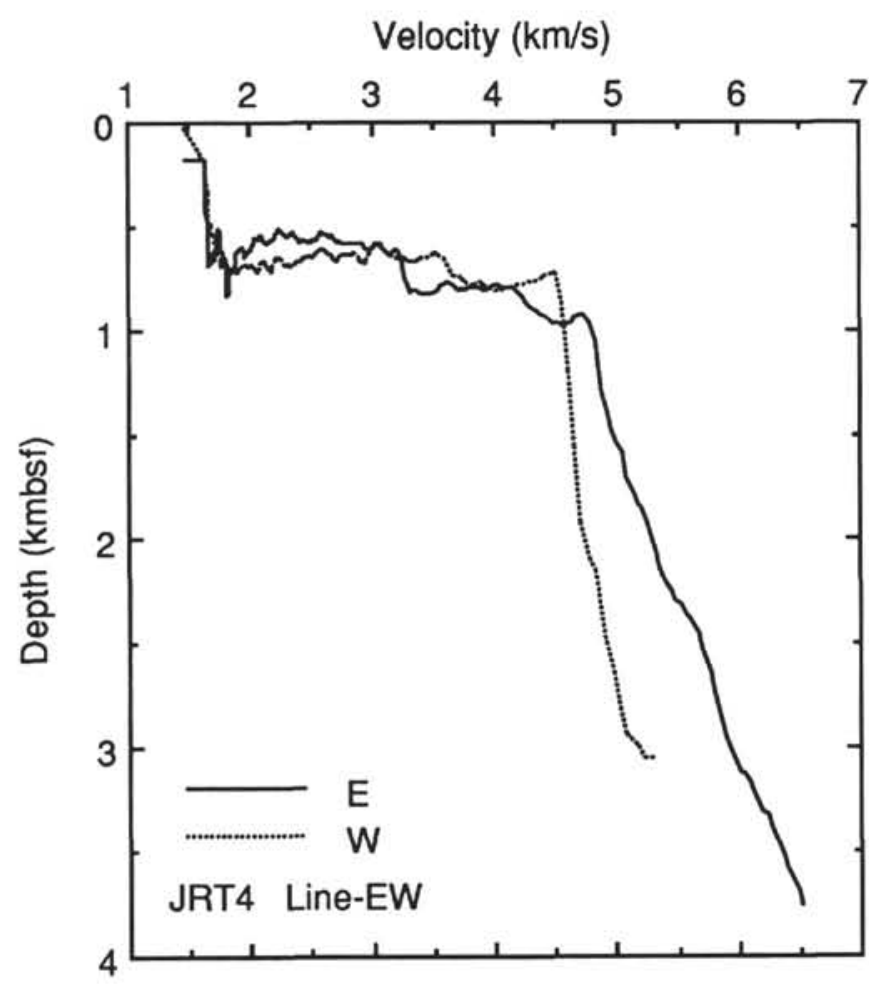

Figure 14. One-dimensional structure models of $P$-wave velocity beneath OBS JRT4. See Figure 13 for detailed explanation.

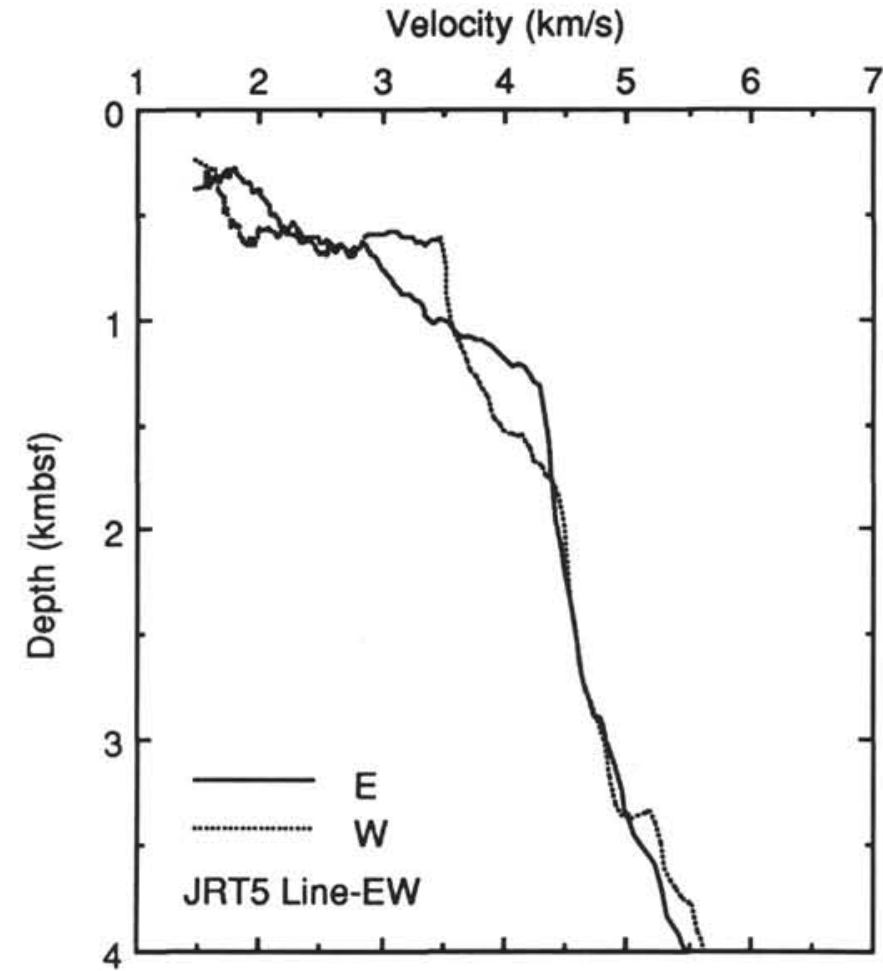

Figure 15. One-dimensional structure models of $P$-wave velocity beneath OBS JRT5. See Figure 13 for detailed explanation. Layer with a $P$-wave velocity of $3.0-4.5 \mathrm{~km} / \mathrm{s}$ underlies the sedimentary layer.

Velocity $(\mathrm{km} / \mathrm{s})$

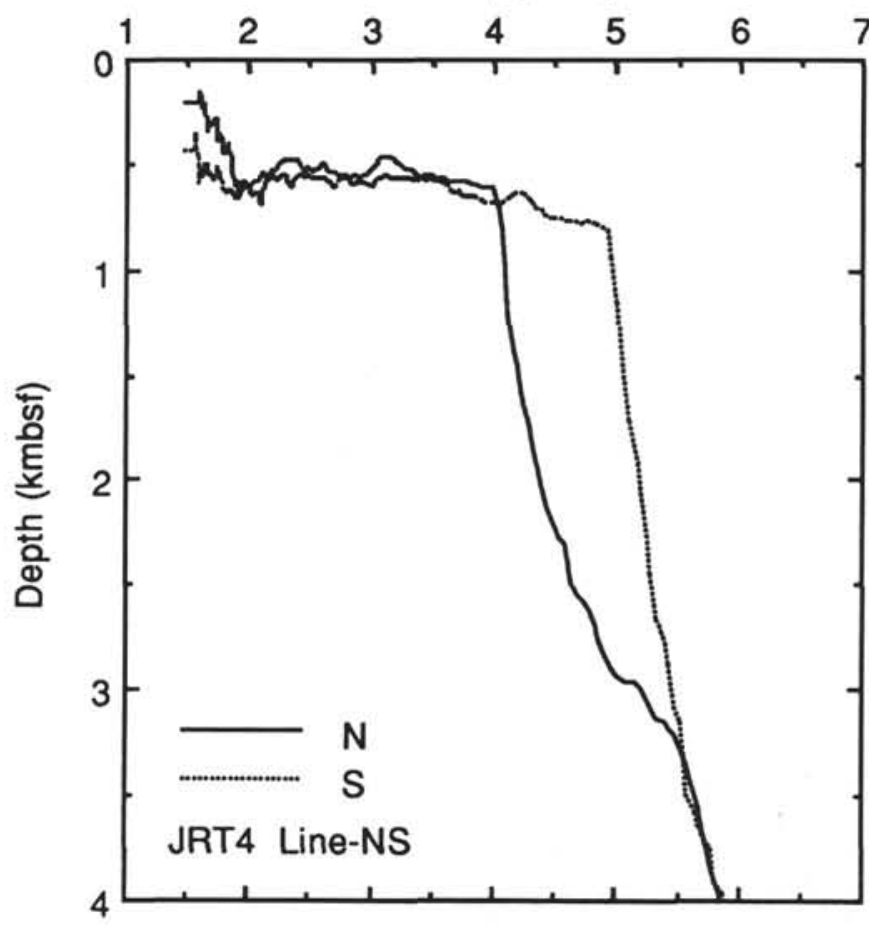

Figure 16. One-dimensional structure models of $P$-wave velocity beneath $\mathrm{OBS}$ JRT4 obtained for each single-sided profile of Line NS. Solid and dash lines correspond to the models derived from records of the northward and southward shots, respectively. 


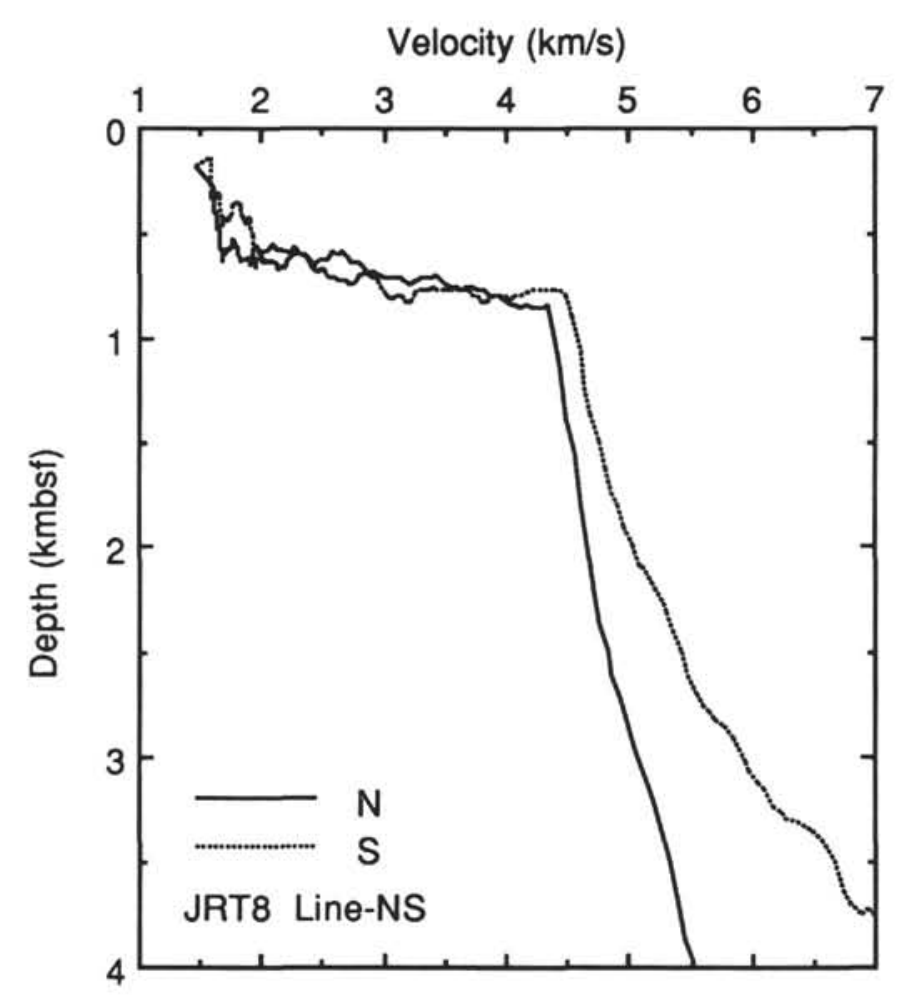

Figure 17. One-dimensional structure models of $P$-wave velocity beneath OBS JRT8. See Figure 16 for detailed explanation.

One-dimensional seismic velocity structures beneath each OBS were derived using the tau- $p$ method with the direct tau- $p$ transform. A sedimentary layer with a small velocity gradient exists just beneath seafloor. The sedimentary layer has a velocity of $1.7 \mathrm{~km} / \mathrm{s}$ and is $200-700 \mathrm{~m}$ thick. An acoustic basement with a $P$-wave velocity of $4.2-4.5 \mathrm{~km} / \mathrm{s}$ underlies the sedimentary layer. A layer with a velocity of $3 \mathrm{~km} / \mathrm{s}$ exists under the sedimentary layer only beneath JRT5.

Two-dimensional velocity structures along two linear profiles were derived by a forward modeling of the traveltimes using a 2-D ray-tracing method. The $4.5-\mathrm{km} / \mathrm{s}$ layer is $2-3 \mathrm{~km}$ thick. A layer with velocity of $6.2 \mathrm{~km} / \mathrm{s}$ underlies the $4.5-\mathrm{km} / \mathrm{s}$ layer. The velocity gradient of the $6.2-\mathrm{km} / \mathrm{s}$ layer is less than $0.2 \mathrm{~s}^{-1}$, and the thickness of the $6.2-\mathrm{km} / \mathrm{s}$ layer appears to be more than $6 \mathrm{~km}$.

It is clear that the northern Yamato Basin is different from the Japan Basin in crustal thickness. The Japan Basin has a typical oceanic crustal thickness of $8 \mathrm{~km}$. The upper crustal velocity structure of the northern Yamato Basin is similar to that of the southern Yamato Basin, where the crust is neither typical oceanic nor continental.

\section{ACKNOWLEDGMENTS}

We thank the scientists, staff, and crews of JOIDES Resolution, Tansei-maru, and Kaiko-maru 5 for their valuable contributions to the experiment. The controlled-source seismic experiment was supported by the following people, whom we thank: A. Nishizawa, Y. Kaiho, S. Abe, H. Shiobara, R. Hino, and S. Kuramoto. S. Ohmi provided the computer program for the data acquisition system. We thank L. S. L. Kong, whose review helped to improve the manuscript, and $\mathrm{K}$. Tamaki for discussion. The computation was done at the Information Processing Center of Chiba University, the computer facilities of the University of Tokyo, and the computer room of Ocean Research Institute, the University of Tokyo.

\section{REFERENCES}

Abe, K., and Kanamori, H., 1970. Mantle structure beneath the Japan Sea revealed by surface waves. Tokyo Daigaku Jishin Kenkyusho Iho, 48:1011-1021.

Bee, M., and Bibee, L. D., 1989. A seismic refraction study of Cretaceous oceanic lithosphere in the northwest Pacific basin. Mar. Geophys. Res., 11:239-261.

Byrne, D. A., Harris, D., Duennebier, F. K., and Cessaro, R., 1987. The ocean sub-bottom seismometer system installed in Deep Sea Drilling Project Hole 581C, Leg 88: a technical review. In Duennebier, F. K., Stephen, R., et al., Init. Repts. DSDP, 88: Washington (U.S. Govt. Printing Office), 65-89.

Červeńy, V., and P̌̌enčik, I., 1983. Program SEIS83, Numerical Modeling of Seismic Wave Fields in 2-D Laterally Varying Layered Structures by the Ray Method: Praha (Charles Univ.).

Chung, T. W., Hirata, N., and Sato, R., 1990. Two-dimensional $P$ - and $S$-wave velocity structure of the Yamato Basin, the southeastern Japan Sea, from refraction data collected by an ocean bottom seismographic array. J. Phys. Earth, 38:99-147.

Diebold, J. B., and Stoffa, P. L., 1981. The traveltime equation, tau-p mapping, and inversion of common midpoint data. Geophysics, 46:238-254.

Duennebier,F. K., Lienert, B., Cessaro, R., Anderson, P., and Mallick, S., 1987. Controlled-source seismic experiment at Hole 581C. In Duennebier, F. K., Stephen, R., et al., Init. Repts. DSDP, 88: Washington (U.S. Govt. Printing Office), 105-125.

Evans, J. R., Suyehiro, K., and Sacks, I. S., 1978. Mantle structure beneath the Japan Sea-a re-examination. Geophys. Res. Lett., 5:487-490.

Hirata, N., Kinoshita, H., Suyehiro, K., Suyemasu, M., Matsuda, N., Ouchi, T., Katao, H., Koresawa, S., and Nagumo, S., 1987. Report on DELP 1985 cruises in the Japan Sea Part II: seismic refraction experiment conducted in the Yamato Basin, southeast Japan Sea. Tokyo Daigaku Jishin Kenkyusho Iho, 62:347-365.

Hirata, N., and Shinjo, N., 1986. SEISOBS-modified version of SEIS 83 for ocean bottom seismograms. Jishin 2, 39:317-321. (in Japanese)

Hirata, N., Tokuyama, H., and Chung, T. W., 1989. An anomalously thick layering of the crust of the Yamato Basin, southeastern Sea of Japan: the final stage of back-arc spreading. Tectonophysics, 165:303-314.

Ingle, J. C., Jr., Suyehiro, K., von Breymann, M. T., et al., 1990. Proc. ODP, Init. Repts., 128: College Station, TX (Ocean Drilling Program).

Isezaki, N., 1975. Possible spreading centers in the Japan Sea. Mar. Geophys. Res., 2:265-277.

Isezaki, N., Hata, K., and Uyeda, S., 1971. Magnetic survey of the Japan Sea (Part 1). Tokyo Daigaku Jishin Kenkyusho Iho, 49:77-83.

Isezaki, N., and Uyeda, S., 1973. Geomagnetic anomaly pattern of the Japan Sea. Mar. Geophys. Res., 2:51-59.

Jacobson, R. S., Adair, R., and Orcutt, J., 1984. Preliminary seismic refraction results using a borehole seismometer in Deep Sea Drilling Project HOLE 395A. In Hyndman, R. D., Salisbury, M. H., et al., Init. Repts. DSDP, 78 (Pt. 2): Washington (U.S. Govt. Printing Office), 783-792.

Kanazawa, T., 1986. Seven-component low-power acoustic release ocean bottom seismograph. Annu. Meet. Seismol. Soc. Jpn. Abstr., 2. (Abstract, in Japanese)

Katao, H., 1988. Seismic structure and formation of the Yamato Basin. Tokyo Daigaku Jishin Kenkyusho Iho, 63:51-86.

Little, S. A., and Stephen, R. A., 1985. Costa Rica Rift borehole seismic experiment, Deep Sea Drilling Project Hole 504B, Leg 92. In Anderson, R. N., Honnorez, J., et al., Init. Repts. DSDP, 83: Washington (U.S. Govt. Printing Office), 517-528.

Ludwig, W. L., Murauchi, S., and Houtz, R. E., 1975. Sediments and structure of the Japan Sea. Geol. Soc. Am. Bull., 86:651-664.

Matsuda, N., Fujii, T., and Kinoshita, H., 1986. Pop-up ocean bottom seismometer with hydrophone system. Annu, Meet. Seismol. Soc. Jpn. Abstr., 2:241. (Abstract, in Japanese)

Murauchi, S., 1972. Seismic crustal structure of the Japan Sea by controlledsource experiment. Kagaku, 42:367-375. (in Japanese)

Neidell, N. S., and Taner, M. T., 1971. Semblance and other coherency measures for multichannel data. Geophysics, 36:483-497.

Okada, H., Moriya, T., Masuda, T., Hasegawa, T., Asano, S., Kasahara, K., Ikami, A., Aoki, H., Sasaki, Y., Furukawa, N., and Matsumura, K., 1978. 
Velocity anisotropy in the Sea of Japan as revealed by big explosions. $J$. Phys. Earth, 26, Suppl.:491-502.

Otofuji, Y., and Matsuda, T., 1984. Timing of rotational motion of Southwest Japan inferred from paleomagnetism. Earth Planet. Sci. Lett., 70:373-382.

1987. Amount of clockwise rotation of Southwest Japan-fan shaped opening of the southwestern part of the Japan Sea. Earth Planet. Sci. Lett., 85:289-301.

Otofuji, Y., Matsuda, T., and Nohda, S., 1985. Paleomagnetic evidence for Miocene counter-clockwise rotation of Northeast Japan-rifting process of the Japan Arc. Earth Planet. Sci. Lett., 75:265-277.

Seama, N., and Isezaki, N., 1990. Sea-floor magnetization in the eastern part of the Japan Basin and its tectonic implications. Tectonophysics, 181:285-297.

Shearer, P., and Orcutt, J., 1985. Anisotropy in the oceanic lithosphere-theory and observations from the Ngendei seismic refraction experiment in the south-west Pacific. Geophys. J. R. Astron. Soc., 80:493-526.

Shearer, P. M., Adair, R. G., Orcutt, J. A., and Jordan, T. H., 1986a. Simultaneous borehole and ocean bottom seismometer recordings of earthquakes and explosions: results from the 1983 NGENDEI experiment at Deep Sea Drilling Project Hole 595B. In Duennebier, F. K., Stephen, R., Gettrust, J, F., et al., Init. Repts. DSDP, 91: Washington (U.S. Govt. Printing Office), 377-383.

Shearer, P. M., Orcutt, J. A., Jordan, T. H., Whitmarsh, R. B., Kim, I. I., Adair, R. G., and Burnett, M. S., 1986b. The NGENDEI seismic refraction experiment at deep sea drilling project Hole 595B - ocean bottom seismometer data and evidence for crustal and upper mantle anisotropy, In Duennebier, F. K., Stephen, R., Gettrust, J. F., et al., Init. Repts. DSDP, 91: Washington (U.S. Govt. Printing Office), 385-399.

Shinohara, M., Amishiki, T., Hino, R., Hirata, N., and Kinoshita, H., 1989. Digital data acquisition system for single channel reflection experiment using a micro computer. Annu. Meet. Seismol. Soc. Jpn. Abstr., 2:259. (Abstract, in Japanese)

Stephen, R. A., 1985. Seismic anisotropy in the upper oceanic crust. $J$. Geophys. Res., 90:11383-11396.

-, 1988. Lateral heterogeneity in the upper oceanic crust at Deep Sea Drilling Project site 504. J. Geophys. Res., 93:6571-6584.

Stephen, R. A., and Harding, A. J., 1983. Travel time analysis of borehole seismic data. J. Geophys. Res., 88:8289-8298.

Stephen, R. A., Johnson, S., and Lewis, B., 1983. The oblique seismic experiment on Deep Sea Drilling Project Leg 65. In Lewis, B.T.R., Robinson, P., et al., Init. Repts. DSDP, 65: Washington (U.S. Govt. Printing Office), 319-327.
Stoffa, P. L., Buhl, P., Diebold, J. B., and Wenzel, F., 1981. Direct mapping of seismic data to the domain of intercept time and ray parameter-a planewave decomposition. Geophysics, 46:255-267.

Swift, S. A., and Stephen, R. A., 1989. Lateral heterogeneity in the seismic structure of upper oceanic crust, Western North Atlantic. J. Geophys. Res., 94:9303-9322.

Swift, S. A., Stephen, R. A., and Hoskins, H., 1988. Structure of upper oceanic crust from an oblique seismic experiment at Hole 418A, Western North Atlantic. In Salisbury, M. H., Scott, J. H., et al., Proc. ODP, Sci. Results, 102: College Station, TX (Ocean Drilling Program), 97-124.

Tamaki, K., 1986. Age estimation of the Japan Sea on the basis of stratigraphy, basement depth, and heat flow data. J. Geomagn. Geoelectr., 38:427-446.

Urabe, T., and Hirata, N., 1984. A playback system for long-term analog tape recordings of ocean bottom seismographs. Jishin 2, 37:633-645. (in Japanese)

Whitmarsh, R. B., Orcutt, J. A., Jordan, T. H., Adair, R. G., and Shearer, P. M. 1986. Velocity bounds on the seismic structure of Mesozoic crust and upper mantle in the southwest Pacific basin from downhole observations at Deep Sea Drilling Project Hole 595B. In Duennebier, F. K., Stephen, R., Gettrust, J. F., et al., Init. Repts. DSDP, 91: Washington (U.S. Govt. Printing Office), 437-444.

Yamada, T., 1980. Spatial distribution of microearthquakes and crust in the subduction area revealed by ocean seismographic observations [Ph.D. dissert.]. Univ. Tokyo. (in Japanese)

Yamano, M., Uyeda, S., Uyeshima, M., Kinoshita, M., Nagihara, S., Boh, R., and Fujisawa, H., 1987. Report on DELP 1985 cruises in the Japan Sea. Part V: heat flow measurements. Tokyo Daigaku Jishin, Kenkyusho Iho, 62:417-432.

Yasui, M., Kishii, T., Watanabe, T., and Uyeda, S., 1968. Heat flow in the Sea of Japan. In The Crust and Upper Mantle of the Pacific Area. Am. Geophys. Union Monogr., 12:3-16.

Yoshii, T., 1972. Terrestrial heat flow and features of the upper mantle beneath the Pacific and Sea of Japan. J. Phys. Earth, 20:271-285.

Date of initial receipt: 26 March 1991

Date of acceptance: 1 September 1991

Ms 127/128B-230 

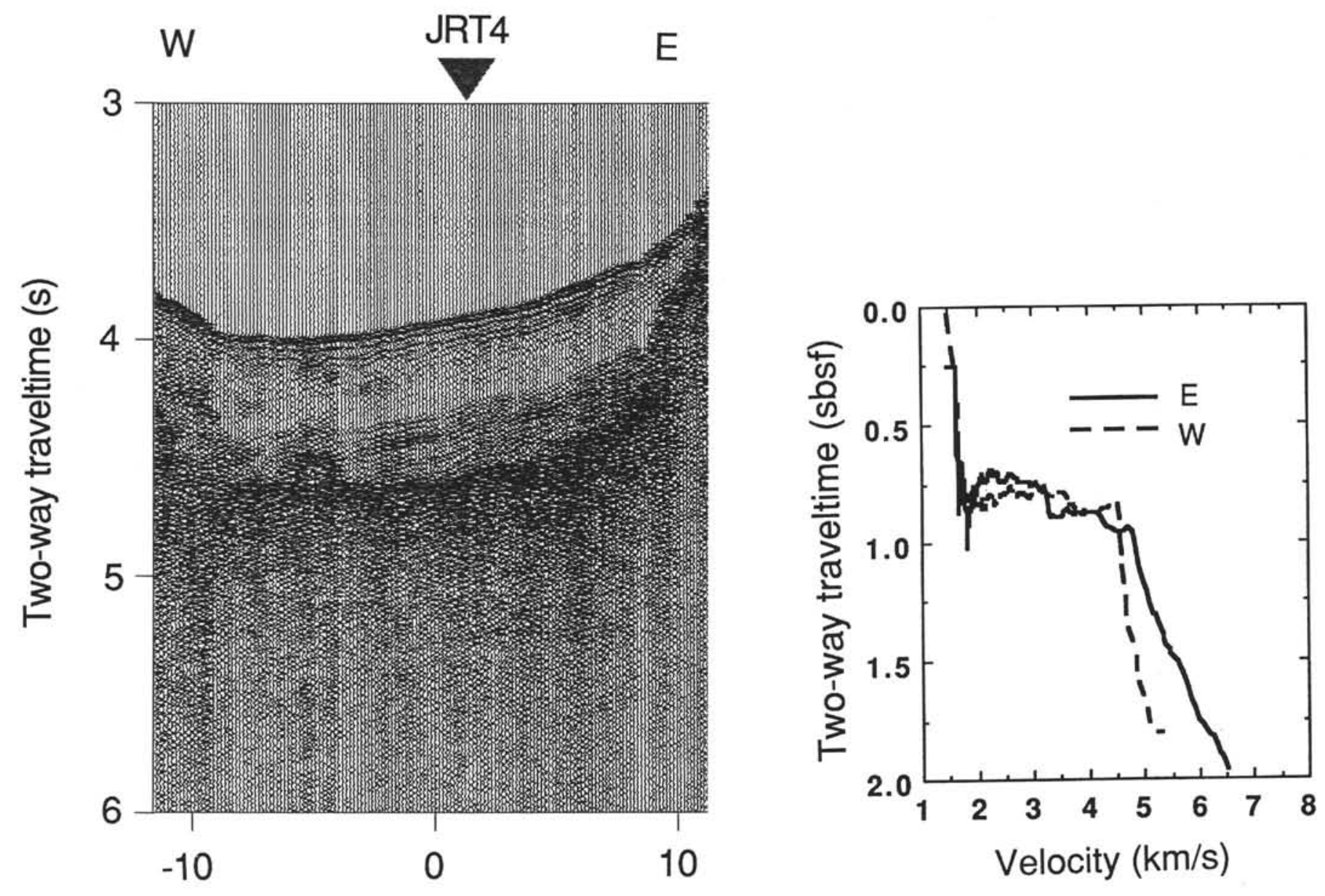

\section{Distance (km)}

Figure 18. Comparison of the reflection records with the tau- $p$ method results for JRT4 Line EW. The one-dimensional structure model of Figure 14 has been converted to two-way traveltime measured from the seafloor. Solid and dash lines correspond to the models derived from records of the eastward and westward shots, respectively. Position of OBS is marked. $P$-wave velocity rapidly increases at the acoustic basement. $P$-wave velocities in the sedimentary layer and uppermost part of acoustic basement are 1.7 and $4.5 \mathrm{~km} / \mathrm{s}$, respectively. 

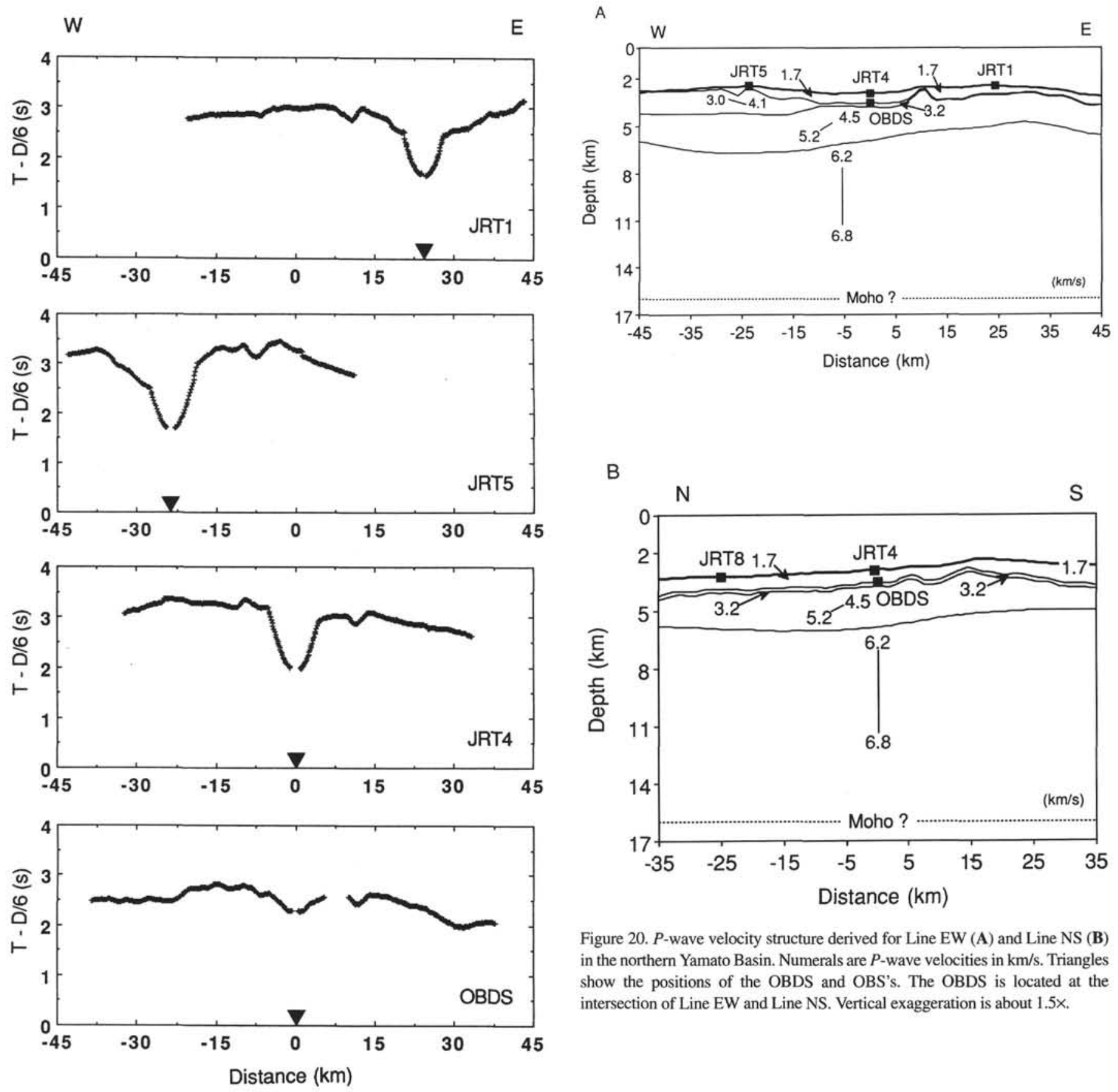

Figure 20. $P$-wave velocity structure derived for Line EW (A) and Line NS (B) in the northern Yamato Basin. Numerals are $P$-wave velocities in $\mathrm{km} / \mathrm{s}$. Triangles show the positions of the OBDS and OBS's. The OBDS is located at the intersection of Line EW and Line NS. Vertical exaggeration is about 1.5×.

Figure 19. Examples of traveltimes of first arrivals on the OBDS and OBS's for Line EW. Origin of abscissa is at the OBDS position. Solid triangles show the positions of each OBS. A phase with an apparent velocity of about $6.0-7.0$ $\mathrm{km} / \mathrm{s}$ is seen in all records. 
A

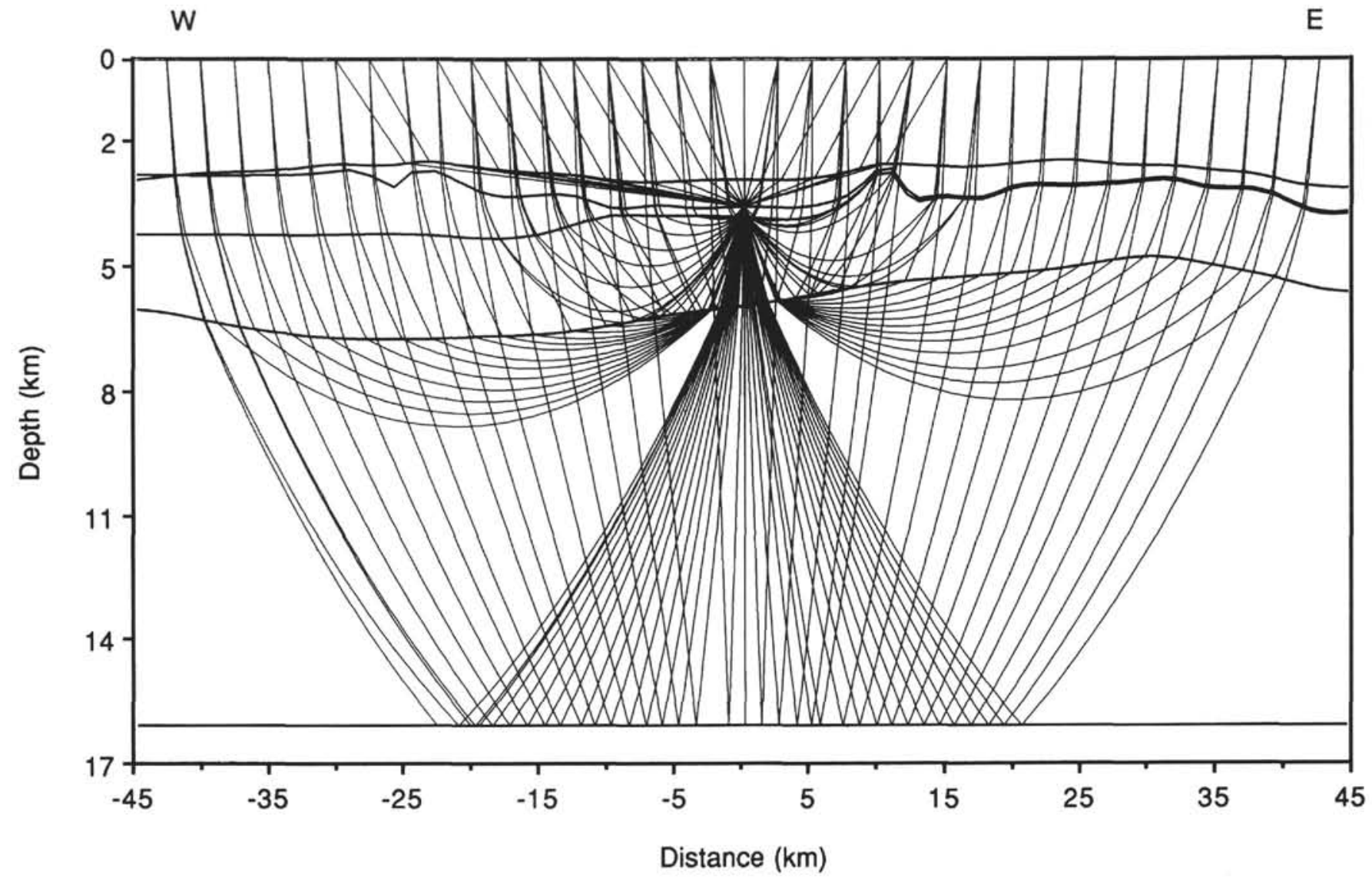

Figure 21. Results of ray tracing using the Line EW model to the OBDS. Distance (D) along the profile Line EW is measured from the OBDS. The OBDS is at $\mathrm{D}=0.0 \mathrm{~km}$. A: Ray path diagrams. B: Observed traveltimes (solid squares) with arrival time reading errors and calculated traveltimes for the model (other symbols). Reading errors of later arrivals are more than $0.5 \mathrm{~s}$ and are not shown. Open squares indicate traveltime of water waves. Crosses, triangles, and circles denote traveltimes of reflection and refraction waves from basement, $4.5-\mathrm{km}$ layer, and $6.2-\mathrm{km}$ layer, respectively. 
B

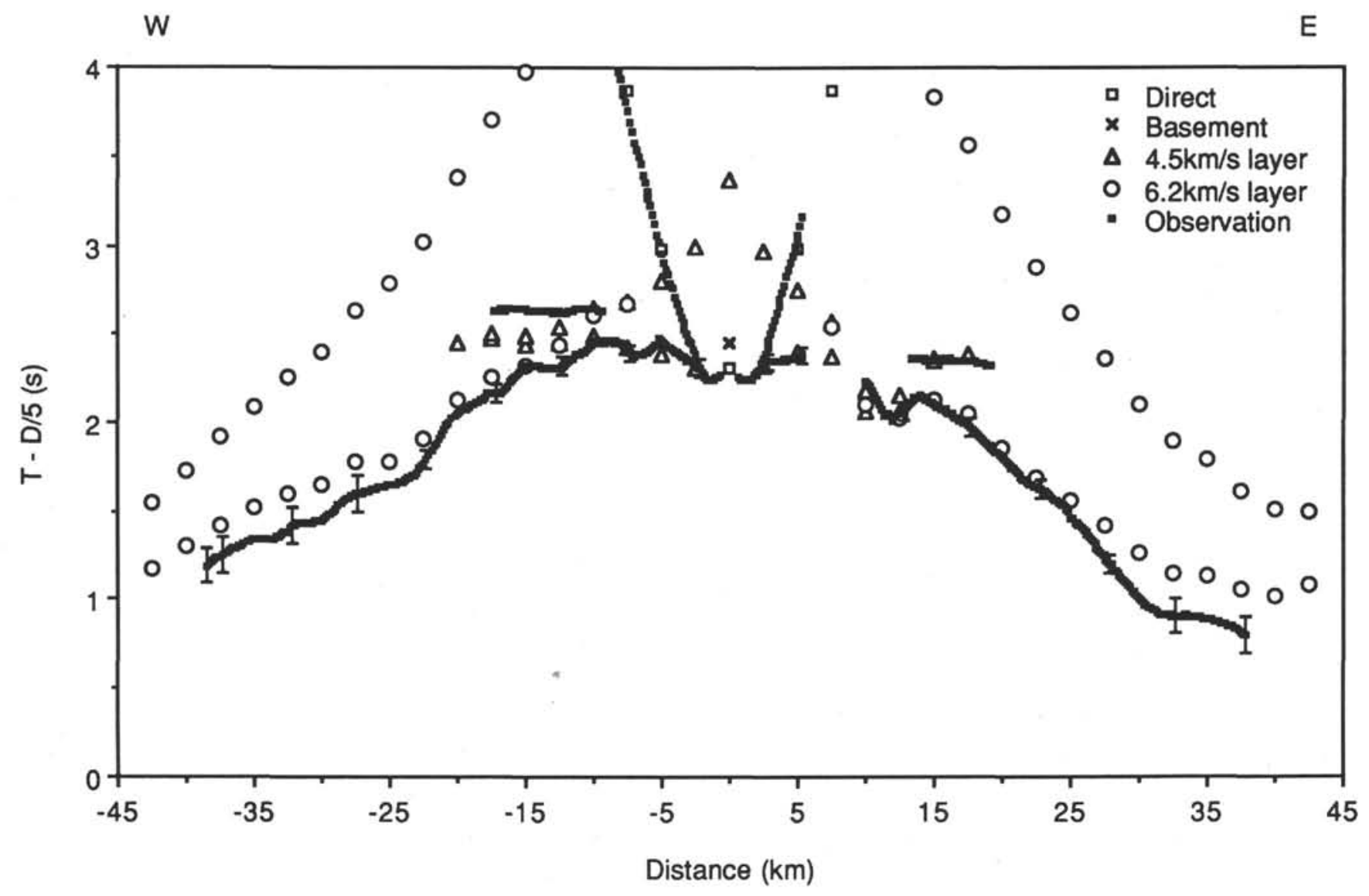

Figure 21 (continued). 


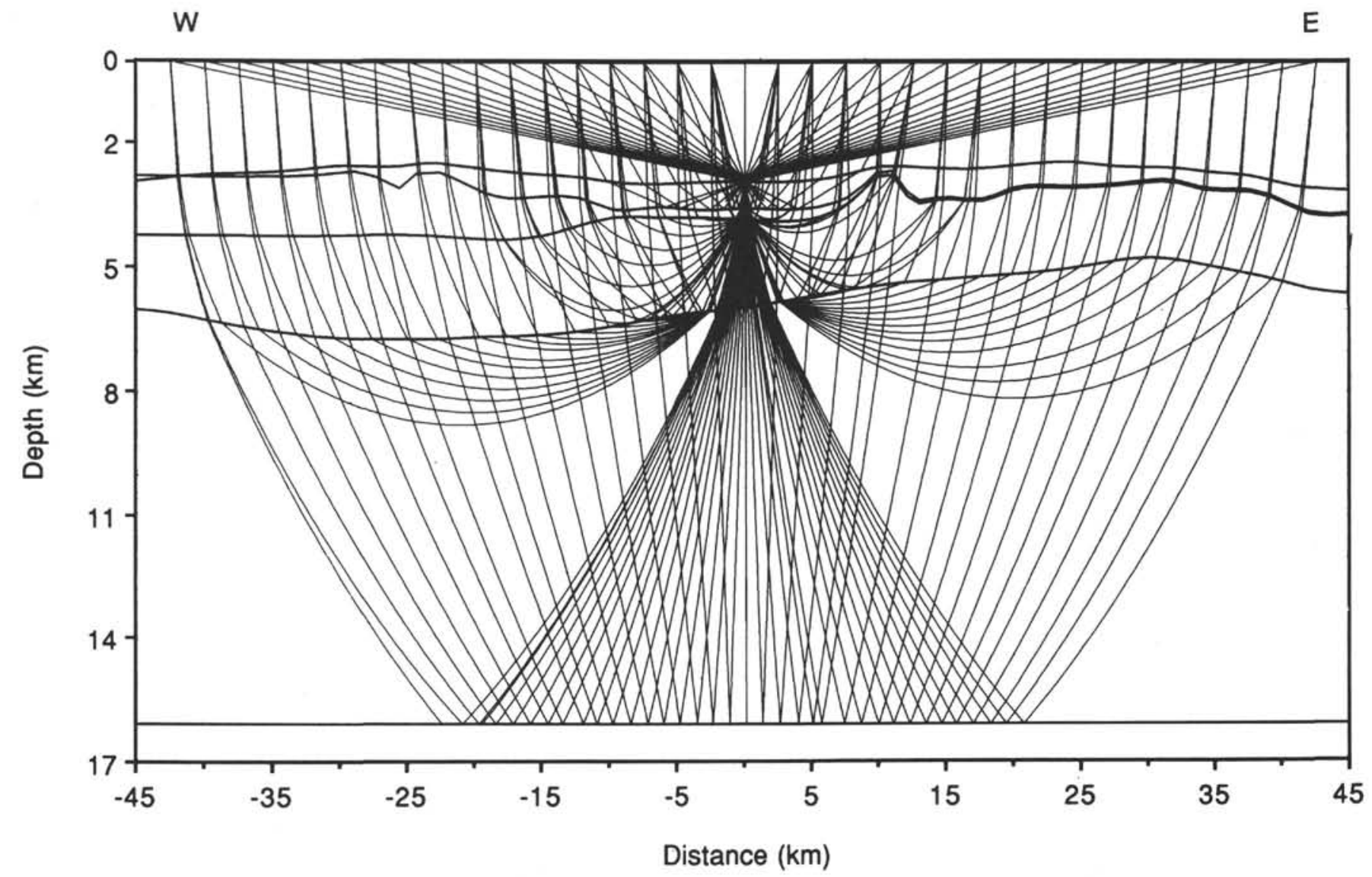

Figure 22. Results of ray tracing using the Line EW model to OBS JRT4 located at D $=0.0 \mathrm{~km}$. See Figure 21 for detailed explanation. 


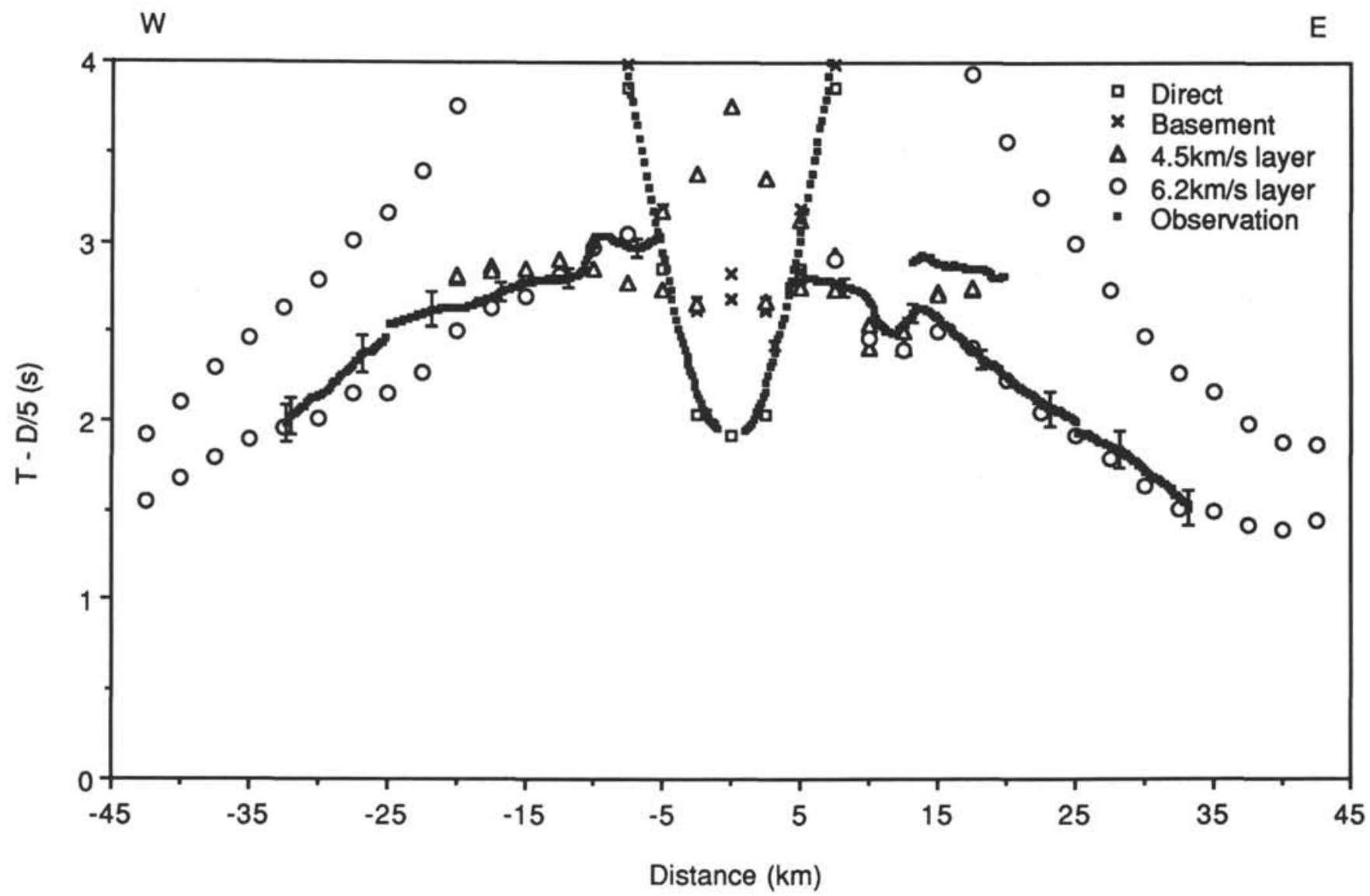

Figure 22 (continued). 


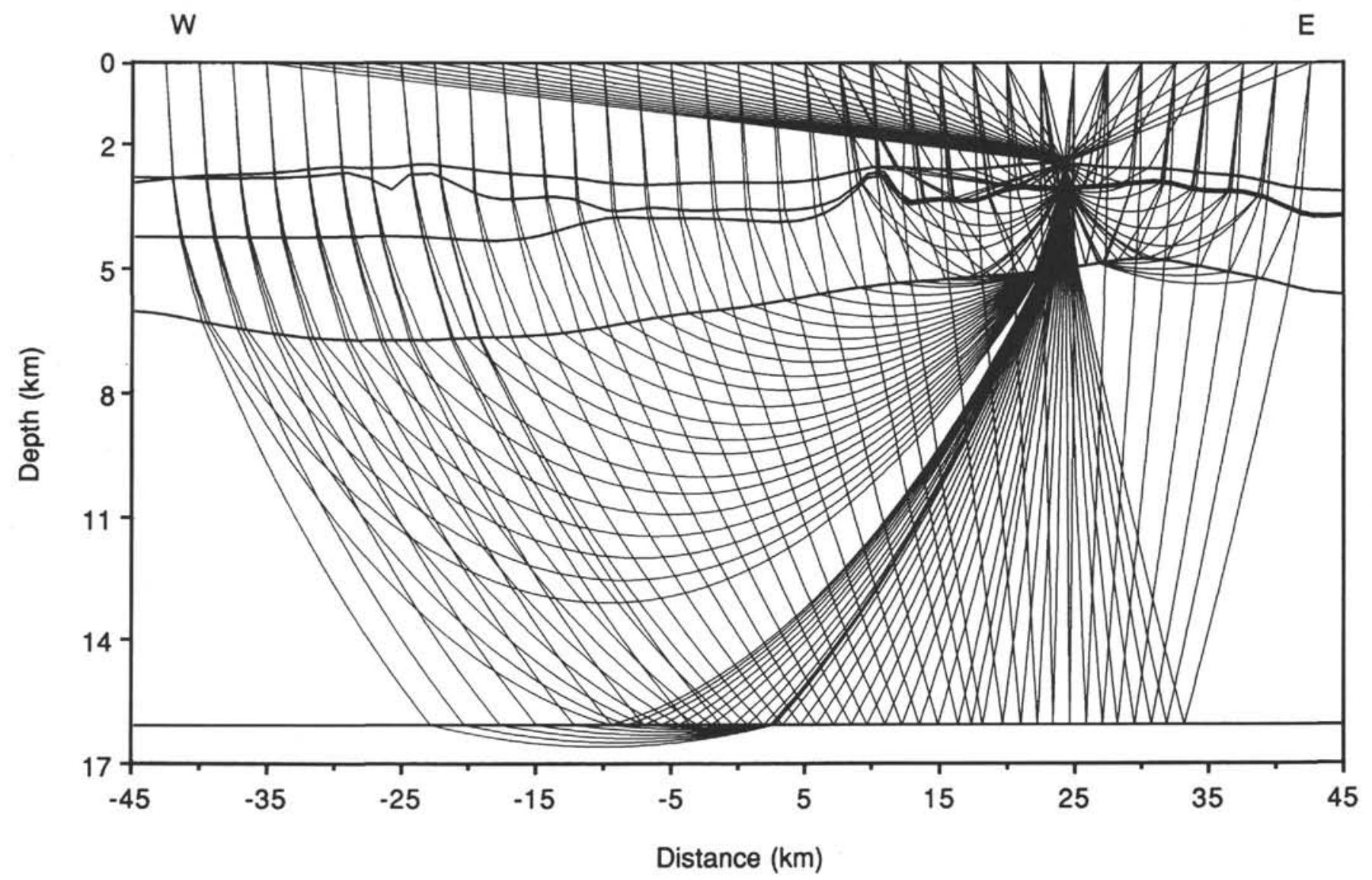

Figure 23. Results of ray tracing using the Line EW model to OBS JRT1 located at D = 24.3 km. See Figure 21 for detailed explanation. Pluses indicate traveltime of $P_{\mathrm{n}}$ phase. 


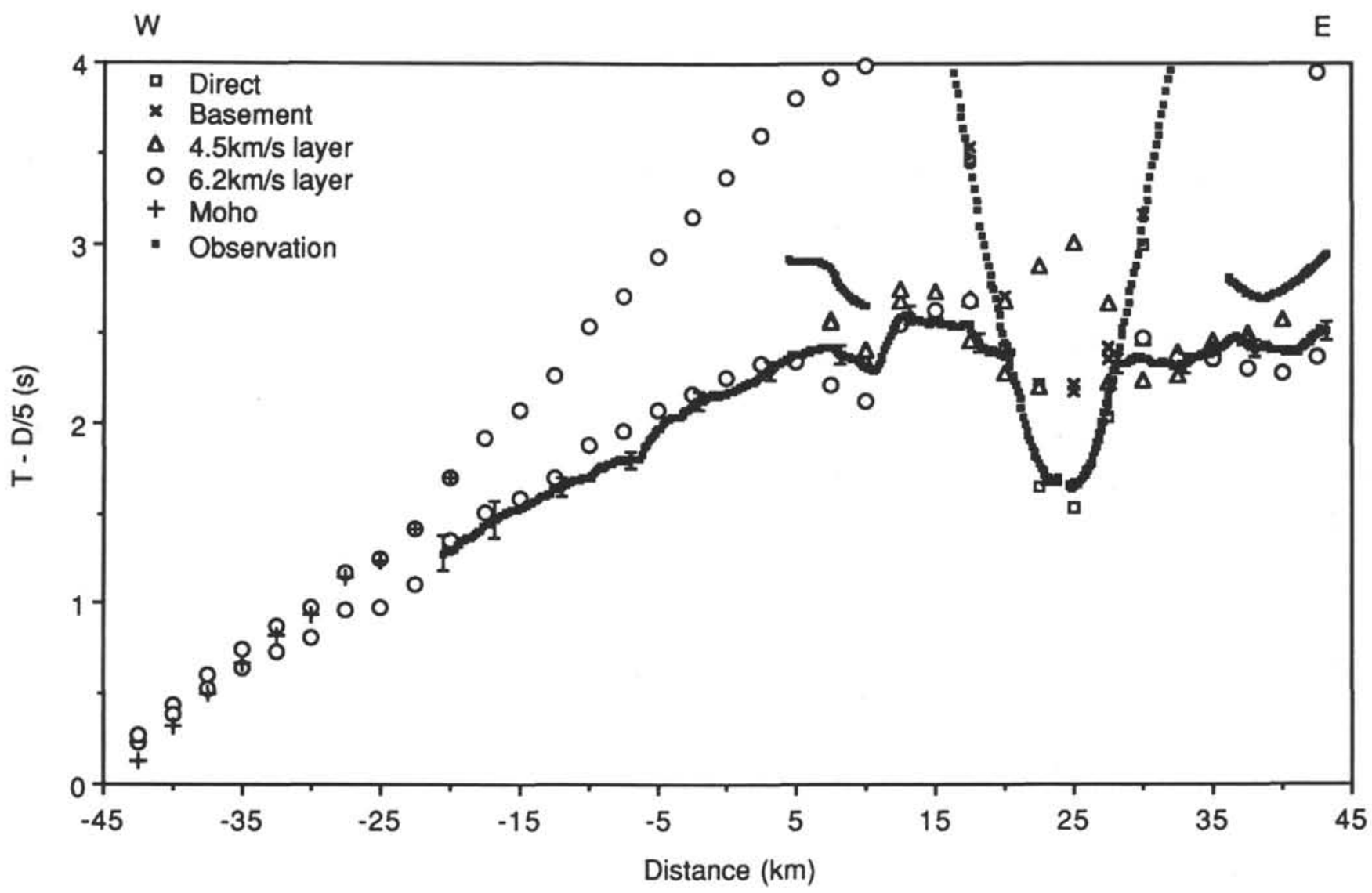

Figure 23 (continued). 


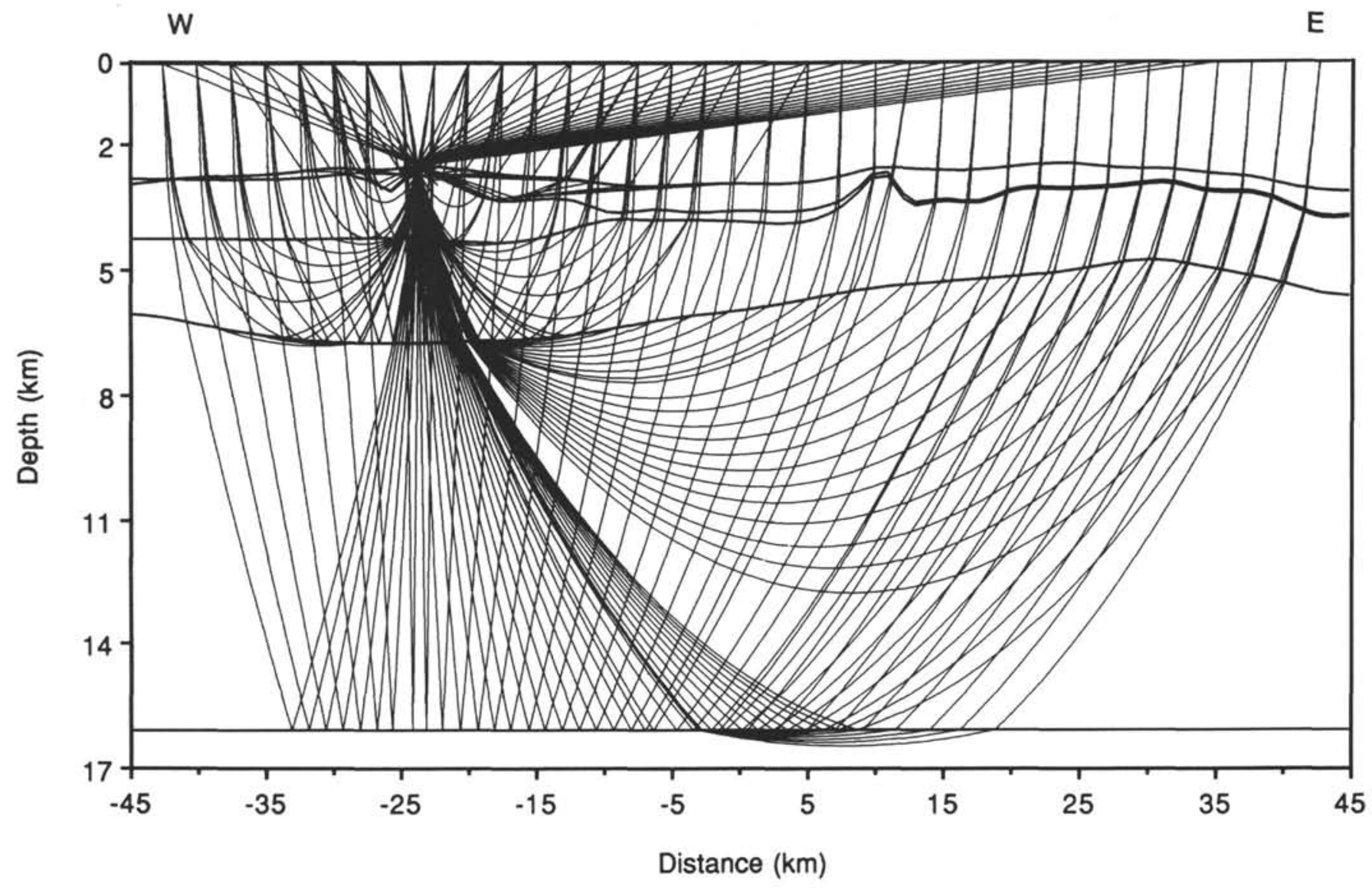

Figure 24. Results of ray tracing using the Line EW model to OBS JRT5 located at D = $-23.7 \mathrm{~km}$. See Figure 21 for detailed explanation. 


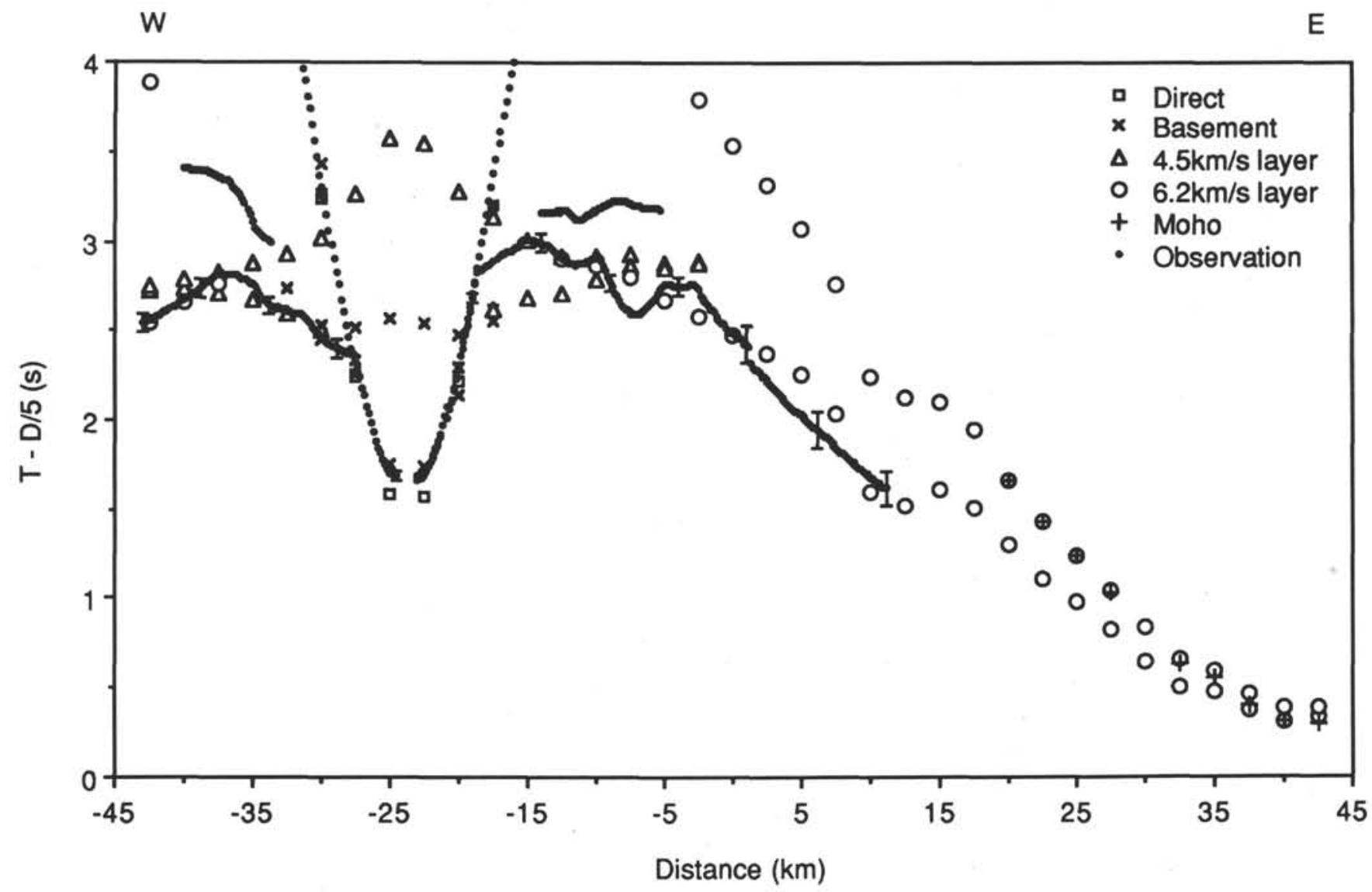

Figure 24 (continued). 


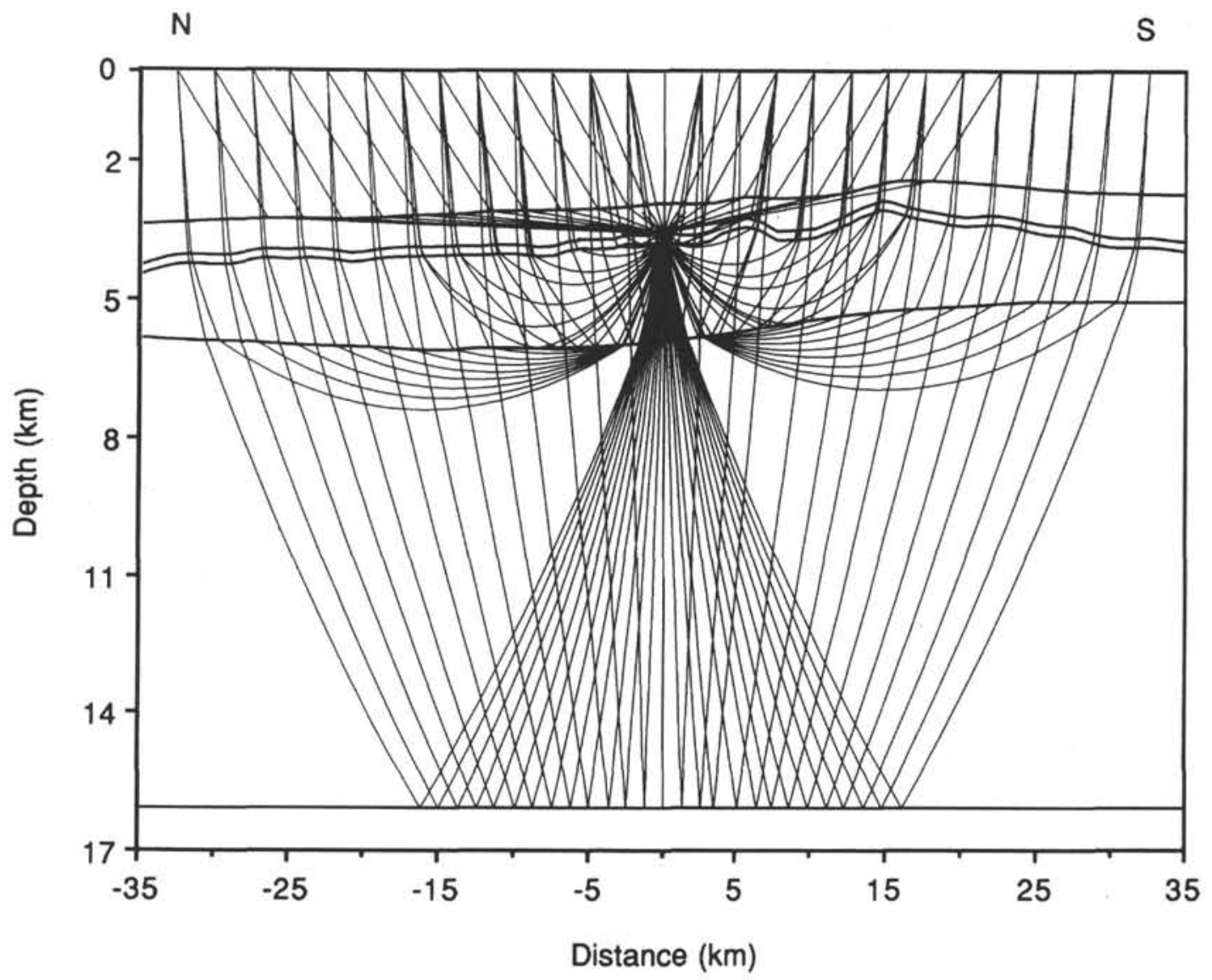

Figure 25. Results of ray tracing using the Line NS to model to the OBDS located at $D=0.0 \mathrm{~km}$. See Figure 21 for detailed explanation. 


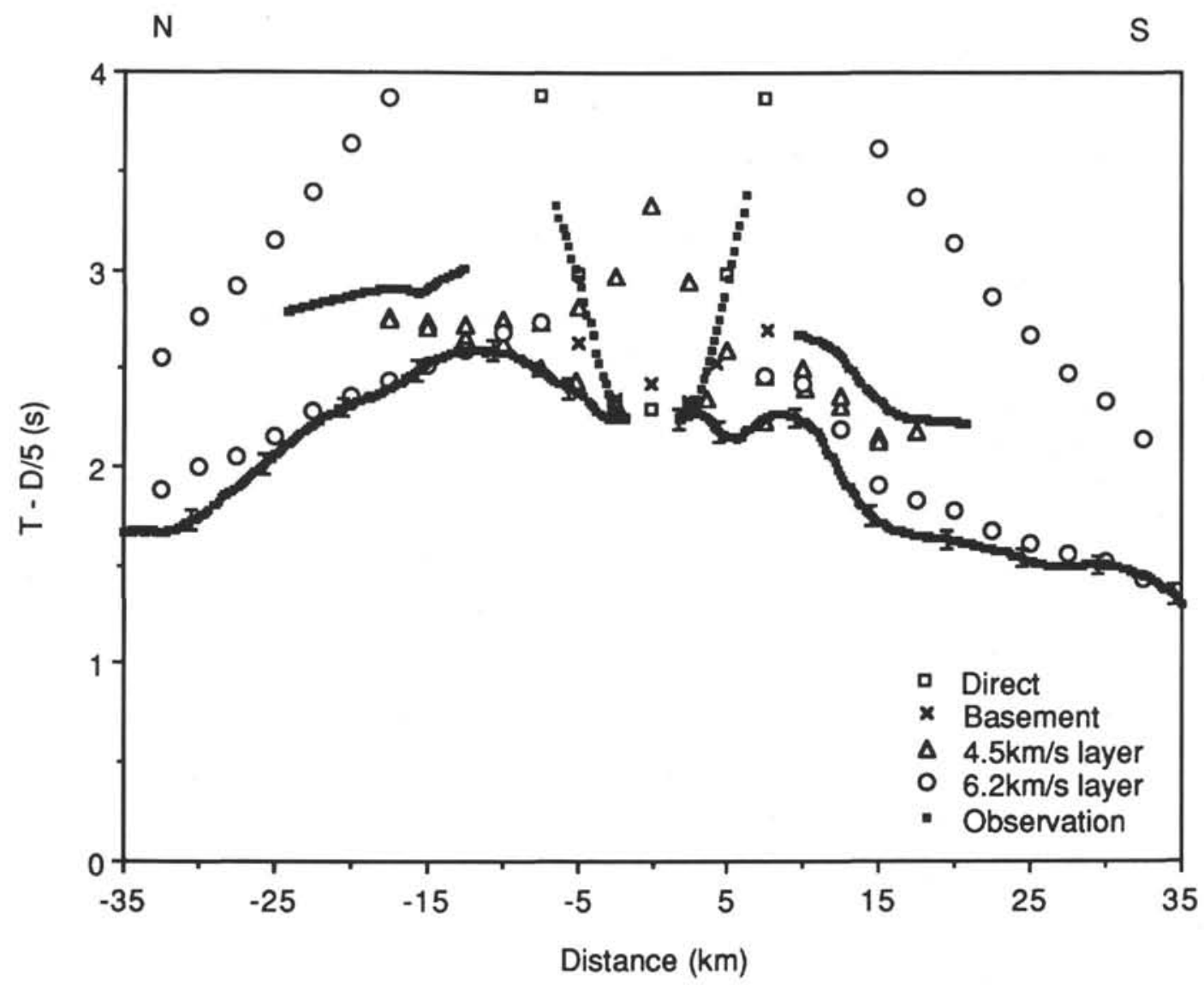

Figure 25 (continued). 


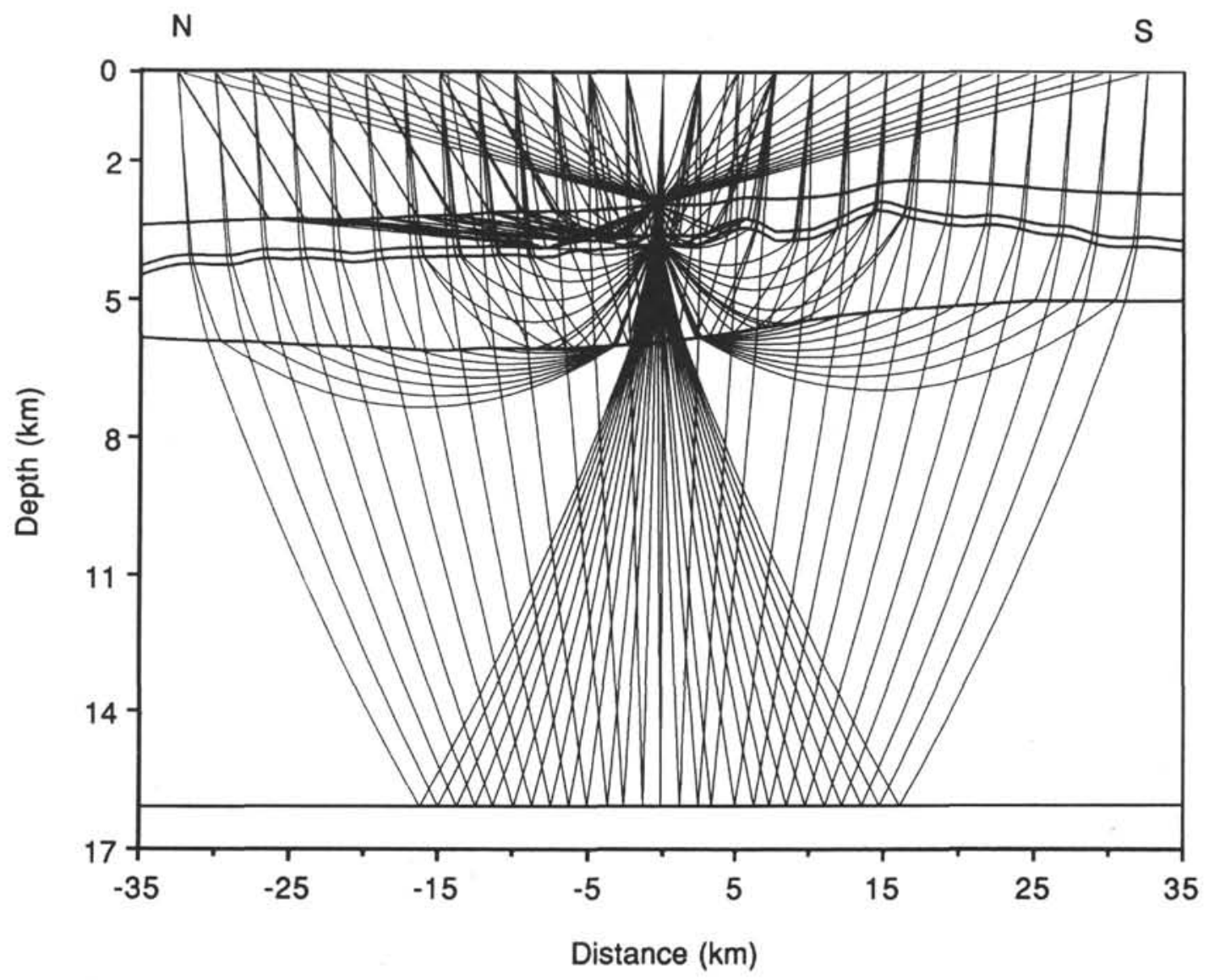

Figure 26. Results of ray tracing using the Line NS model to OBS JRT4 located at $\mathrm{D}=-0.4 \mathrm{~km}$. See Figure 21 for detailed explanation. 
YAMATO BASIN CRUSTAL STRUCTURE

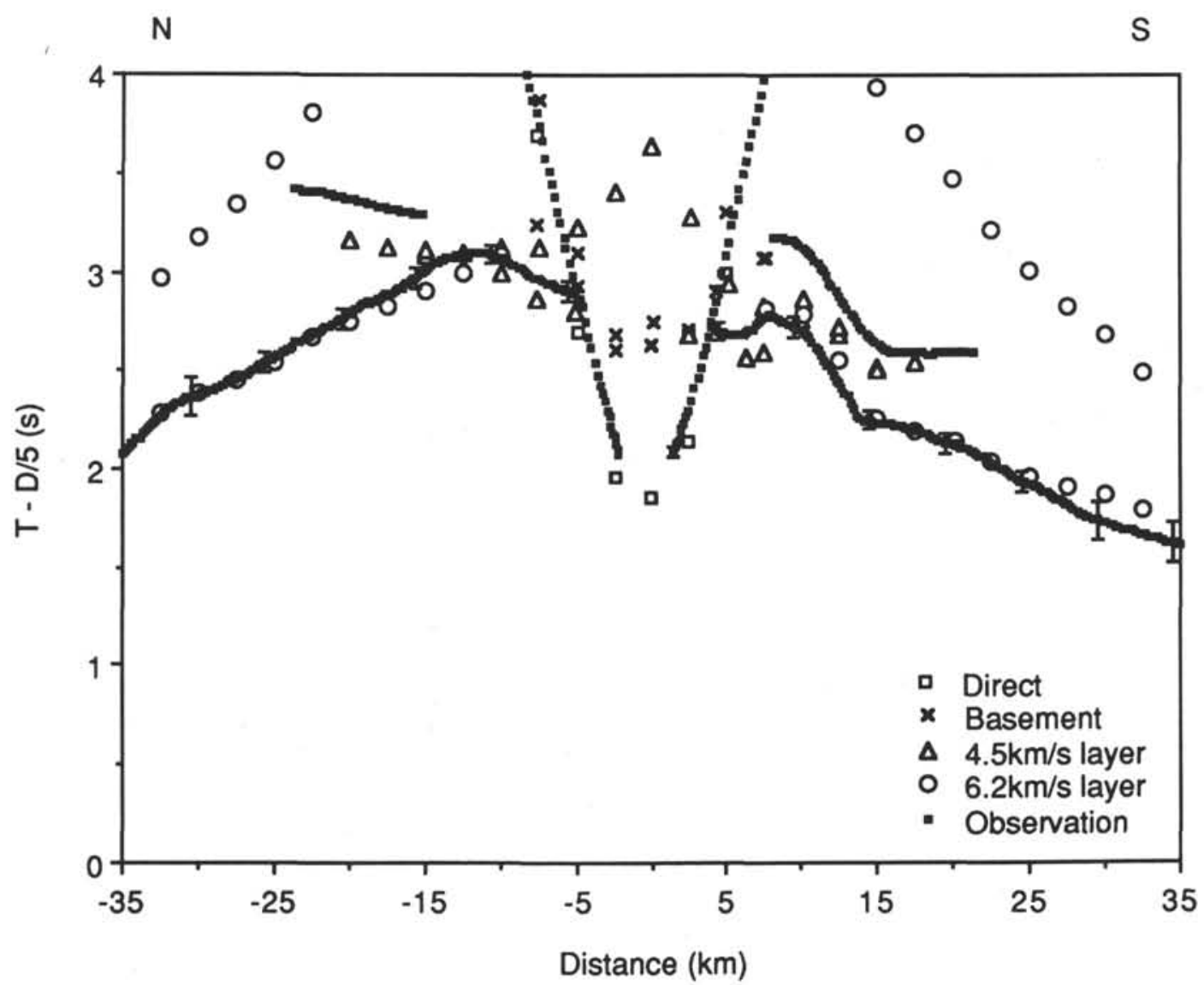

Figure 26 (continued).

1101 


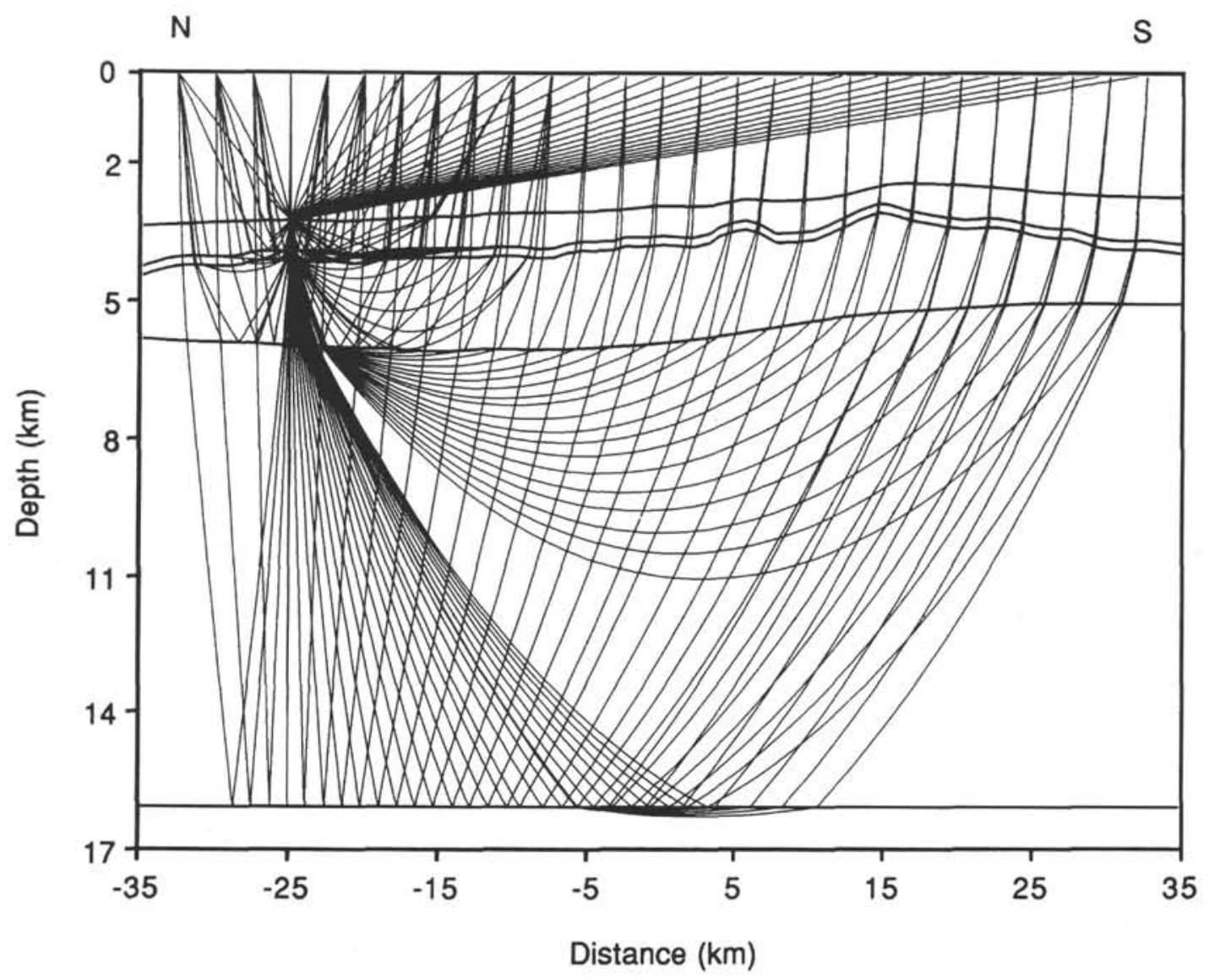

Figure 27. Results of ray tracing using the Line NS model to OBS JRT8 located at D $=25.0 \mathrm{~km}$. See Figure 21 for detailed explanation. 


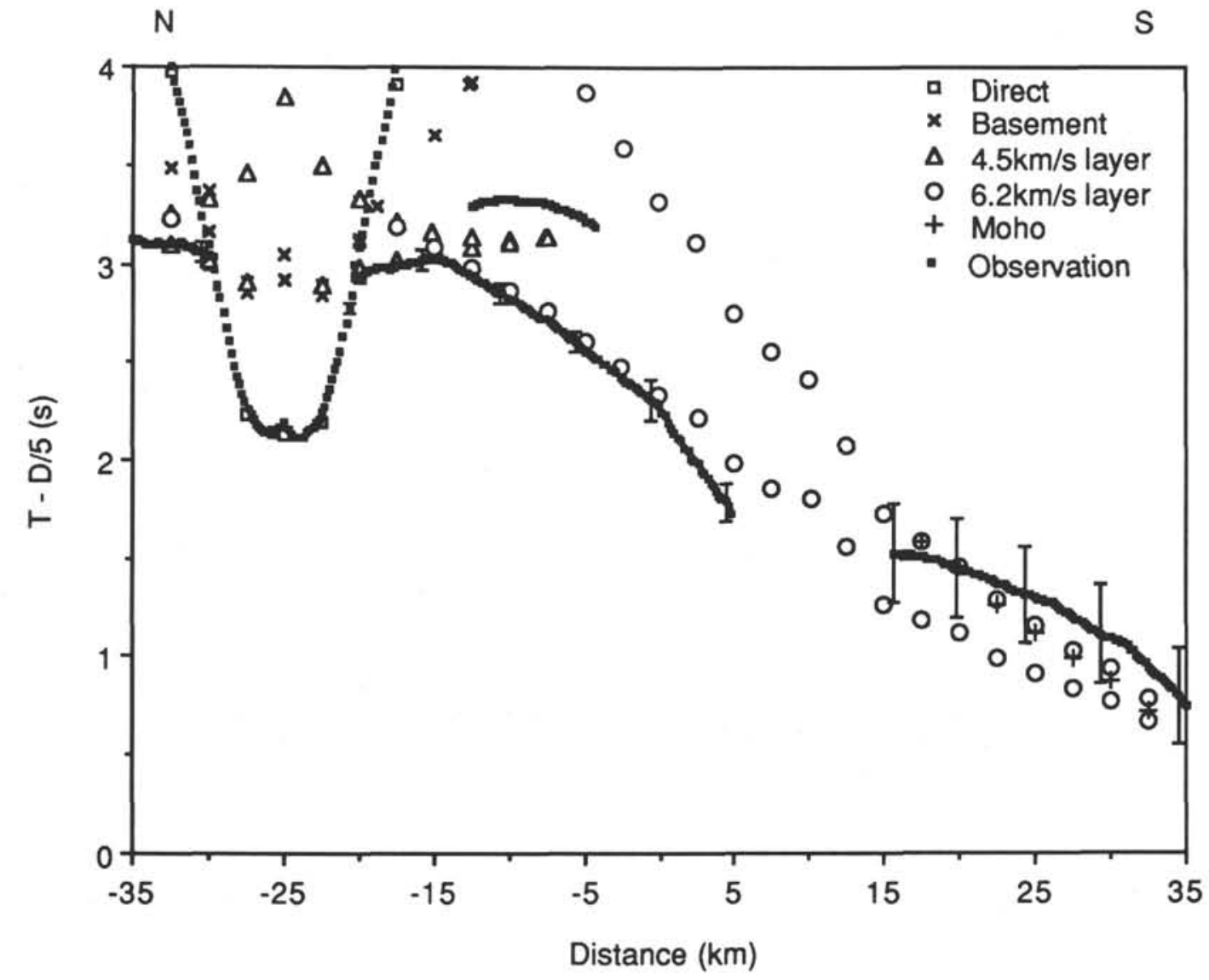

Figure 27 (continued). 
Southern

Yamato Basin
Northern

Yamato Basin
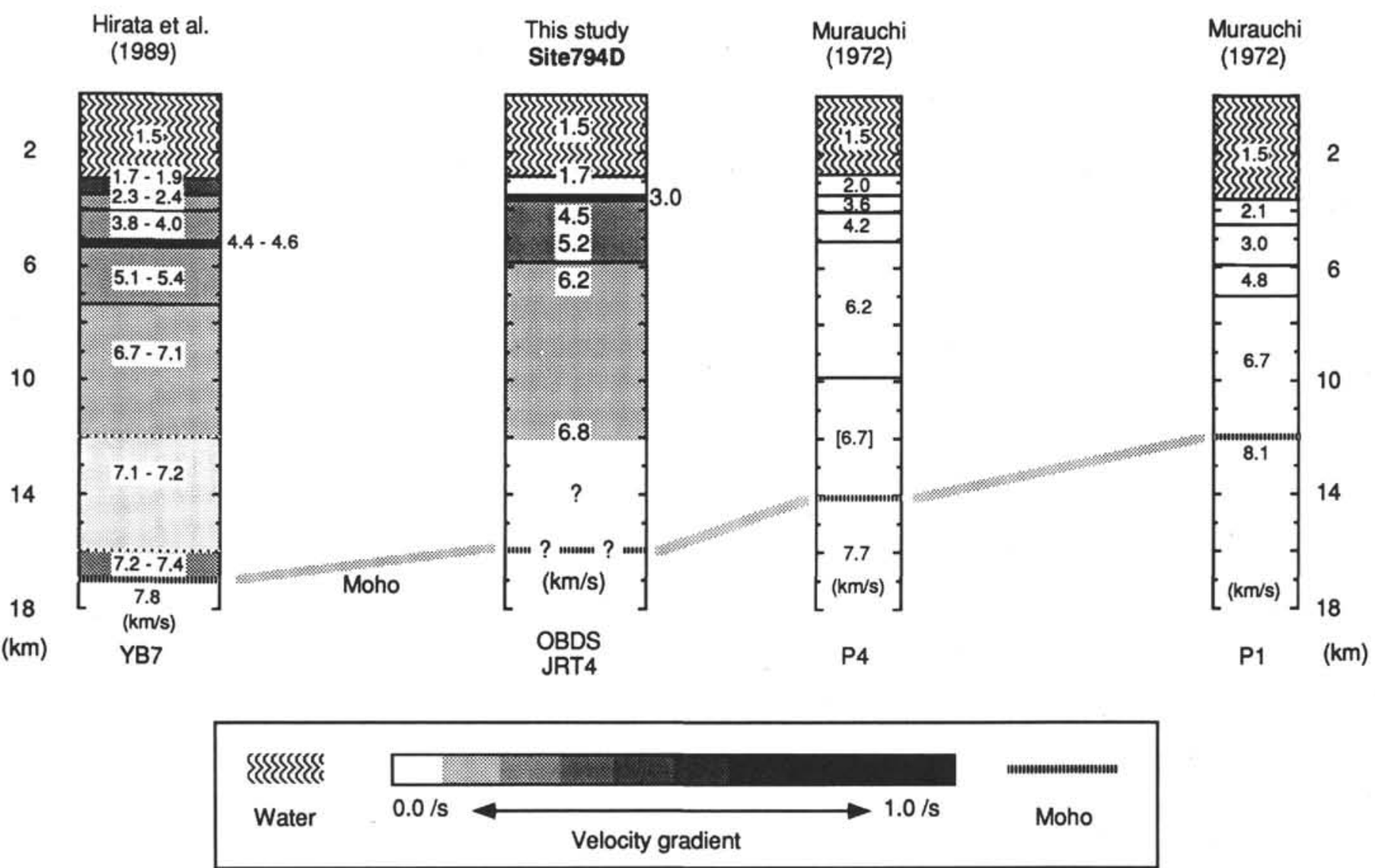

Figure 28. Comparison of the seismic structure of the northern Yamato Basin to structures in other areas of the Japan Sea. YB7 is an OBS station in the 1985 OBS's air-gun and explosion experiment (Hirata et al., 1987). P1 and P4 (Murauchi, 1972) show the results of the two-ship seismic experiments (locations of YB7, P1, and P4 in Fig. 1). The upper crustal structure of the northern Yamato Basin is similar to that of the southern Yamato Basin. A thick sedimentary layer and an upper crust with a large velocity gradient characterize the seismic structure of the Yamato Basin. 


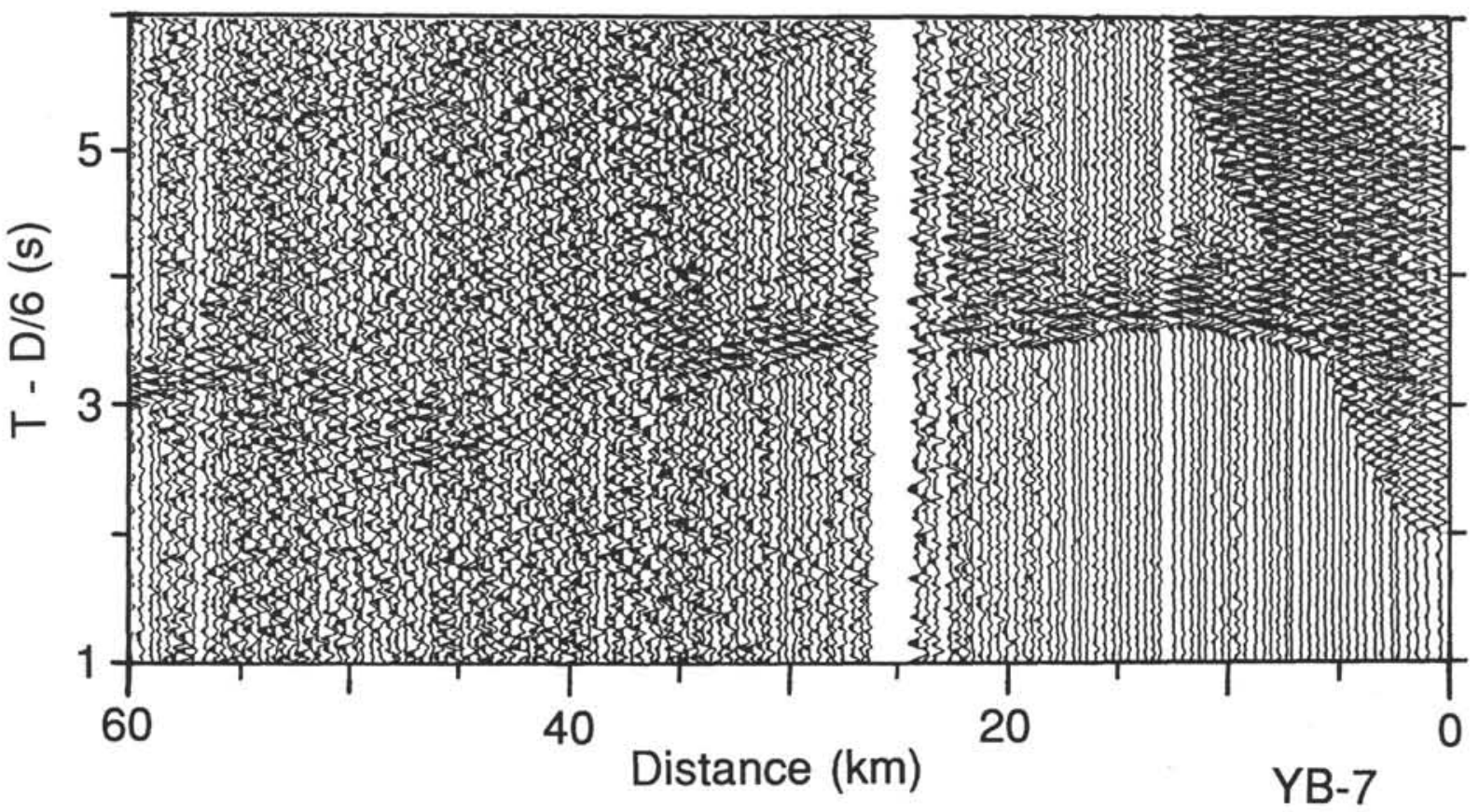

Southern Yamato Basin

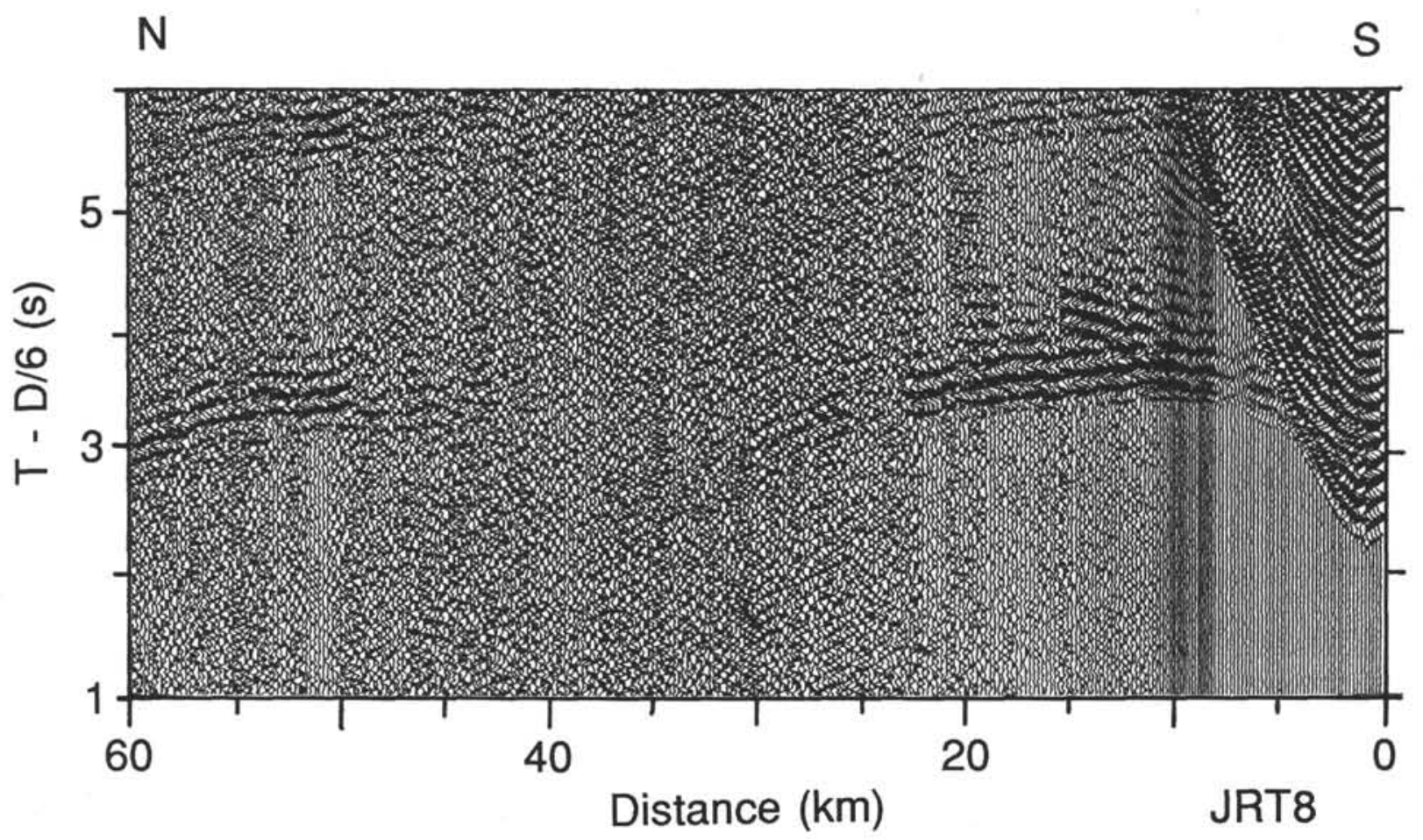

\section{Northern Yamato Basin}

Figure 29. Comparison of seismic data (vertical component, high-gain channel) from JRT8 in the northern Yamato Basin with that from YB7 in the southern Yamato Basin. Reduction velocity is $6.0 \mathrm{~km} / \mathrm{s}$. Band-pass filtering is $5-20 \mathrm{~Hz}$. Records for the southwestward shots of YB7 and northward shots of JRT8 are plotted. A close resemblance between the two record sections is seen at ranges less than $25 \mathrm{~km}$. 


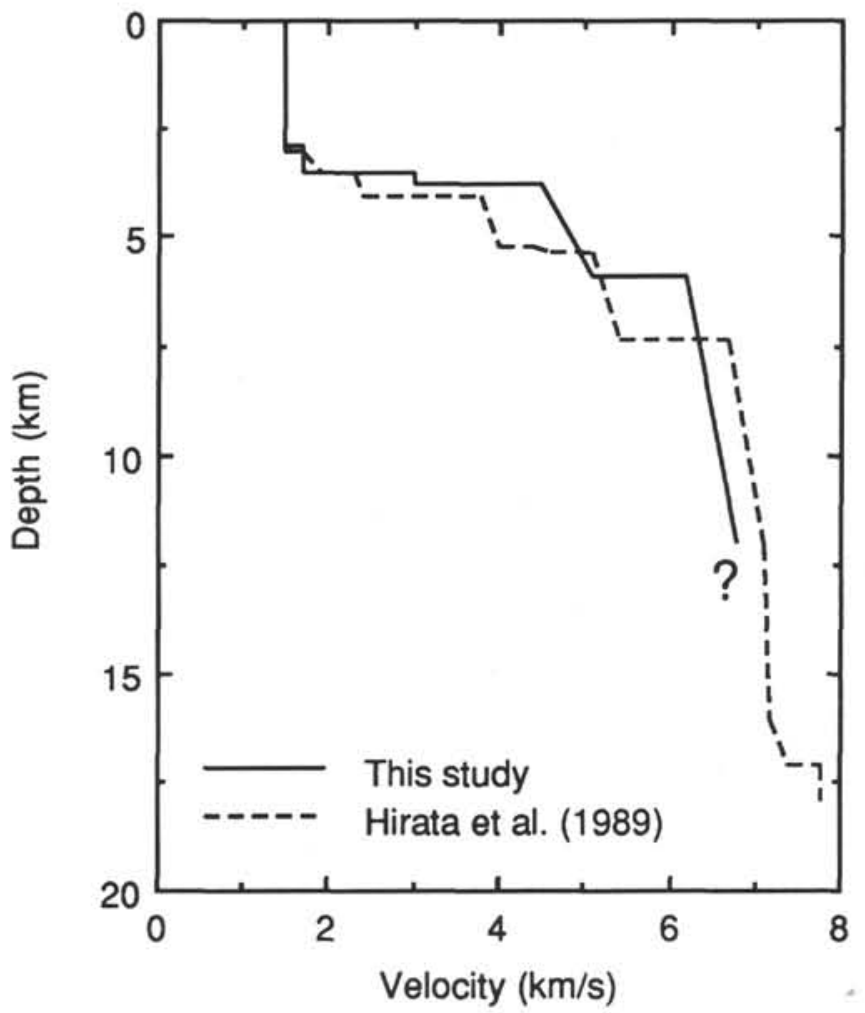

Figure 30. Comparison of $P$-wave velocity-depth functions for the northern Yamato Basin (solid line) and the southern Yamato Basin (dash line). Both crusts have a 1-km-thick sedimentary layer that overlies a layer with a large velocity gradient. 